\title{
Nutritional Aspects of Ecologically Relevant Phytochemicals in Ruminant Production
}

\section{Luis O. Tedeschi ${ }^{1 *}$, James P. Muir ${ }^{2}$, Harley D. Naumann ${ }^{3}$, Aaron B. Norris ${ }^{4}$, Carlos A. Ramirez-Restrepo ${ }^{5}$ and Susanne U. Mertens-Talcott ${ }^{6}$}

${ }^{1}$ Department of Animal Science, Texas A\&M University, College Station, TX, United States, ${ }^{2}$ Texas A\&M Agrilife Research, Stephenville, TX, United States, ${ }^{3}$ Division of Plant Sciences, University of Missouri, Columbia, MO, United States,

${ }^{4}$ Department of Natural Resources Management, Texas Tech University, Lubbock, TX, United States, ${ }^{5}$ CR Eco-efficient Agriculture Consultancy (CREAC) ${ }^{T M}$, Bushland Beach, QLD, Australia, ${ }^{6}$ Department of Nutrition and Food Science, Texas A\&M University, College Station, TX, United States

This review provides an update of ecologically relevant phytochemicals for ruminant production, focusing on their contribution to advancing nutrition. Phytochemicals embody a broad spectrum of chemical components that influence resource competence

OPEN ACCESS

Edited by:

Uchenna Anele,

North Carolina Agricultural and

Technical State University,

United States

Reviewed by:

Elsa Lamy,

University of Évora, Portugal

Jorge Avila Stagno,

University of Concepcion, Chile

Mabrouk Elsabagh,

Kafrelsheikh University, Egypt

*Correspondence:

Luis O. Tedesch

luis.tedeschi@tamu.edu

Specialty section:

This article was submitted to Animal Nutrition and Metabolism,

a section of the journal

Frontiers in Veterinary Science

Received: 11 November 2020

Accepted: 04 February 2021

Published: 05 March 2021

Citation:

Tedeschi LO, Muir JP, Naumann HD, Norris $A B$, Ramírez-Restrepo $C A$ and Mertens-Talcott SU (2021) Nutritional

Aspects of Ecologically Relevant

Phytochemicals in Ruminant

Production. Front. Vet. Sci. 8:628445.

doi: 10.3389/fvets.2021.628445 and biological advantage in determining plant species' distribution and density in different ecosystems. These natural compounds also often act as plant defensive chemicals against predatorial microbes, insects, and herbivores. They may modulate or exacerbate microbial transactions in the gastrointestinal tract and physiological responses in ruminant microbiomes. To harness their production-enhancing characteristics, phytochemicals have been actively researched as feed additives to manipulate ruminal fermentation and establish other phytochemoprophylactic (prevent animal diseases) and phytochemotherapeutic (treat animal diseases) roles. However, phytochemical-host interactions, the exact mechanism of action, and their effects require more profound elucidation to provide definitive recommendations for ruminant production. The majority of phytochemicals of nutritional and pharmacological interest are typically classified as flavonoids (9\%), terpenoids (55\%), and alkaloids (36\%). Within flavonoids, polyphenolics (e.g., hydrolyzable and condensed tannins) have many benefits to ruminants, including reducing methane $\left(\mathrm{CH}_{4}\right)$ emission, gastrointestinal nematode parasitism, and ruminal proteolysis. Within terpenoids, saponins and essential oils also mitigate $\mathrm{CH}_{4}$ emission, but triterpenoid saponins have rich biochemical structures with many clinical benefits in humans. The anti-methanogenic property in ruminants is variable because of the simultaneous targeting of several physiological pathways. This may explain saponin-containing forages' relative safety for long-term use and describe associated molecular interactions on all ruminant metabolism phases. Alkaloids are $\mathrm{N}$-containing compounds with vast pharmacological properties currently used to treat humans, but their phytochemical usage as feed additives in ruminants has yet to be exploited as they may act as ghost compounds alongside other phytochemicals of known importance. We discussed strategic recommendations for phytochemicals to support sustainable ruminant production, such as replacements for antibiotics and anthelmintics. Topics that merit further examination are discussed and include the role 
of fresh forages vis-à-vis processed feeds in confined ruminant operations. Applications and benefits of phytochemicals to humankind are yet to be fully understood or utilized. Scientific explorations have provided promising results, pending thorough vetting before primetime use, such that academic and commercial interests in the technology are fully adopted.

Keywords: feed additive, methods, nutrition, rumen modifiers, ruminants, antinutritive factor

\section{INTRODUCTION}

Ideal anaerobic fermentation in the rumen relies on a steady supply of substrate (i.e., quantity and frequency), preservation of a favorable condition for microbial growth (e.g., temperature, $\mathrm{pH}$, substrate mixing), and constant removal of undesirable substances (e.g., bacterial toxins, hydrogen), so that the profile and amount of volatile fatty acids (VFA) produced and microbial protein leaving the rumen meets the ruminant's daily requirements for energy and protein without having deleterious impacts in the rumen health and functionality (e.g., rumenitis) $(1,2)$. Although the rumen can function adequately if these conditions are met, it may not be operating at its maximum anaerobic efficiency. Thus, some dietary tweaking might achieve maximum anaerobic efficiency or maintain a healthy operational rumen.

This is where feed additives, also known as rumen modifiers, come into play. If the feed additive is of plant origin, i.e., phytogenic, they are collectively referred to as phytochemicals. Some usually refer to them as plant secondary metabolites because they are not associated with essential roles in the plant, such as photosynthesis, respiration, and growth and development (3). However, the distinction between primary and secondary metabolites is obscure and relative to the plant's physiological needs. For instance, environmental conditions and ecological niches drive the synthesis of different phenolics that are entrenched in the plant's genome based on their evolutionary strategies, but the reasons for evolutionary demands, however, are unclear (4).

Phytochemicals of nutritional and pharmacological interest, such as those to prevent (phytochemoprophylaxis) or treat (phytochemotherapeutic) animal diseases, are typically classified as flavonoids (e.g., polyphenolics), terpenoids (e.g., terpenes), and alkaloids (3). Not all phytochemicals have known beneficial properties to ruminants, but those that do so are often grouped as polyphenolics (e.g., hydrolyzable-HT-and condensedCT-tannins), terpenes (e.g., saponins), vitamins, and essential oils (EO). In part, the immense variability in phytochemical biological properties makes it very difficult to catalog them and study their effects on animals of economic relevance.

Flavonoids are polyphenolic compounds comprising fifteen carbons, with two aromatic rings (AC and $\mathrm{B}$ ) connected by a three-carbon bridge, called flavan (Figure 1). About

Abbreviations: AMR, antimicrobial resistance; BW, body weight; CPP, ciliate protozoa population; CT, condensed tannins; DM, dry matter; DMI, dry matter intake; EO, essential oils; GIN, gastrointestinal nematode; HT, hydrolyzable tannin; TPS, triterpenoid saponins; and VFA, volatile fatty acids.
5,000 flavonoids have been isolated (6), and the important ones are assigned to 12 subclasses, including anthocyanidins, aurone, chalcone, coumarin, dihydrochalcone, dihydroflavonol, flavan-3,4-diol, flavan-3-ol, flavanones, flavones, flavonols, and isoflavones $(5,7)$. Polyphenolics (e.g., tannins) comprise a significant subclass of flavonoids (Figure 1). Condensed tannins have been extensively used in ruminants because of their ability to reduce methane $\left(\mathrm{CH}_{4}\right)$ emissions $(8,9)$; shift protein digestion from the rumen to the small intestine $(10,11)$; improve the maternal environment and reproductive efficiency (i.e., ovulation, scanning, pregnancy, and fecundity rates) (12); support early embryonic survival (13); enhance embryo and fetal development, lambing rates, and lamb survival from birth to weaning (12); and trigger blood cell counts and the immune system response (14), among many other applications $(1,15,16)$. Given the broad and sometimes incomplete understanding of CT's impact on the rumen's fermentation dynamics, interest has intensified in their ability to alter animal products' nutritional and organoleptic characteristics. The modulation of ruminal biohydrogenation with consequent alteration of the fatty acid composition of milk and meat is perceived as beneficial to humans because of the relative increase of omega-3, trans-11, and conjugated linoleic and linolenic fatty acids (17). Similarly, of particular interest is the ability of CT to reduce gastrointestinal parasite burdens $(14,18-20)$ given growing concerns of pharmaceutical antiparasitic resistance in grazing ruminants (21) due to their continuous, and sometimes unnecessary, treatment with ivermectin, a macrocyclic lactone.

Approximately 30,000 terpenoids compounds have been identified (6). Among these, saponins are classified into triterpene or steroidal glycosides, having many different biophysicochemical properties. Most studies in ruminants have focused only on saponins' nutritional aspects to prevent digestive disorders when used as feed additives (22). Plant extract is the typical form adopted to achieve the desired phytochemical compound, and five saponin-rich plants have been consistently examined: Camellia sinensis L. (23, 24), Quillaja saponaria (25, 26), and Sapindus rarak DC.-lerak (27, 28) and Sapindus saponaria L.-soapberry $(29,30)$ with a triterpenoid structure; and Yucca schidigera $(31,32)$ with a steroidal nucleus.

In the last 15 years, some advancements in phytochemical research have been motivated by governmental regulations focusing on public health interests, especially those related to antimicrobial resistance (AMR) due to the broad and unbridled use of antibiotics in animal production as well as poorly controlled use for treating humans (16). Therefore, effective antibiotics replacements, including EO (33), such as allicin (garlic 


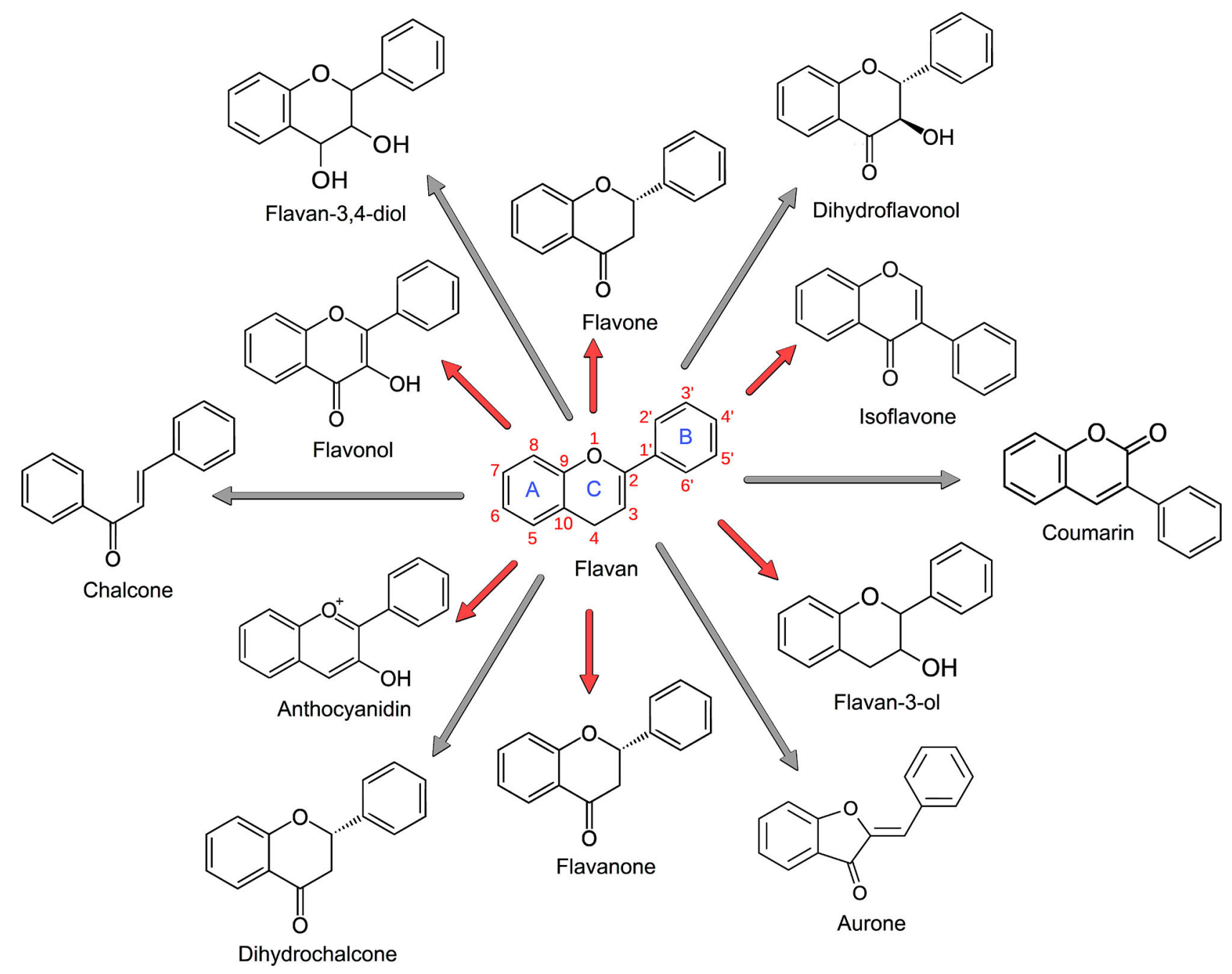

FIGURE 1 | Flavonoid nomenclature. The main subclasses of flavonoids are shown in red arrows, including anthocyanidins, flavan-3-ol, flavanones, flavones, flavonols, and isoflavones. The minor flavonoids are shown in gray arrows, including aurone, chalcone, coumarin, dihydrochalcone, dihydroflavonol, and flavan-3,4-diol. Isoflavones are characterized by having the B-ring attached at $\mathrm{C}_{3}$ rather than the $\mathrm{C}_{2}$ position, and coumarins follow the same structure of isoflavones, except for the double-bond oxygen that is located in $\mathrm{C}_{3}$, not in $\mathrm{C}_{4}$. Based on Hahlbrock (5) and Crozier et al. (3).

extract), carvacrol (oregano extract), cinnamaldehyde (cinnamon extract), and thymol (thyme extract), have been extensively investigated in broilers, pigs, and aquaculture $(34,35)$ due to their bacteriostatic and bactericidal properties. However, ruminant studies, including volatile terpenoids as EO constituents, have yielded mixed results $(34,36)$.

Alkaloids are nitrogen-based chemical compounds synthesized by plants for defensive purposes against predation by an offending organism, such as microorganisms, insects, herbivores, and sometimes, even other plants. Besides the deterrence of predation, there is growing evidence that alkaloids are also produced to harm the offending organism's growth and development through allelopathic action (37). Their toxic effect depends on their type and the amount consumed by the animal, but its primary purpose is to repel feeding via visual or olfactory signals (38). After ingestion and absorption, alkaloids can cause physiological and metabolic changes in the offending organism. Alkaloids can also be produced by animals, insects, and marine vertebrates, although plant extracts are the primary source that has been extensively studied (39). Most studies with alkaloids are related to their toxicological effect on animals rather than their phytochemical feed additive properties. Research on alkaloid pharmaceutical properties in humans was initiated in the 1980s (40). By the early 1990s, about 10,000 alkaloids were cataloged (41), including aconitine (anti-rheumatism), atropine (antispasmodic), caffeine (a stimulant), codeine (analgesic), ephedrine (decongestant), ergotamine (migraine), hydrastine (lower gastrointestinal disorders), and morphine (pain killer) to list a few (42). To date, more than 20,000 alkaloids have been isolated (6). However, few studies were conducted with domesticated animals to improve their production performance, 
or alkaloids have acted as ghost phytochemicals with unknown biological importance.

This review aims to discuss important nutritional and methodological aspects of major phytochemicals relevant to ruminant production, including flavonoids (e.g., polyphenolics), which comprise $9 \%$ of phytochemicals $(5,000$ in 55,000), terpenoids (e.g., saponins, EO, and fat-soluble vitamins), which contain $55 \%$ of phytochemicals $(30,000$ in 55,000$)$, and alkaloids, which comprise $36 \%$ of phytochemicals $(20,000$ in 55,000$)$.

\section{POLYPHENOLICS}

\section{Classification and Definitions}

Polyphenolic plant secondary metabolites are ubiquitous throughout the plant kingdom. Tannins are a subclass in terrestrial plants broadly categorized into two major compounds: CT and HT. Hydrolyzable tannins are esters of gallic acid with a polyol core molecule, commonly glucose, and might be further categorized into ellagitannin, gallotannin, and galloglucose subclasses. Condensed tannins are polymers of flavan-3-ol (Figure 1) with subunits categorized as catechin, epicatechin, gallocatechin, or epigallocatechin. The diversity of the chemical structures of $\mathrm{CT}$ is vast. When considering the multiple subunit and bond types, a simple trimer could represent 1 of nearly 600 different isomers (43). Both CT and HT bind and precipitate protein via hydrogen bonding and hydrophobic interactions (44), a defining characteristic in tannin-ruminant animal interactions.

\section{Nutritional Importance}

The chemical properties of tannins contribute to nutritional and antinutritional effects on ruminant animals. The nutritional importance of tannins largely depends on their ability to bind to macromolecules and mineral nutrients. Condensed tannins and HT readily bind to dietary proteins in ruminants $(45,46)$ and interact with dietary lipids (47), polysaccharides (48), and metal ions (49). Tannins also alter microbiomes and inhibit microbial and enzymatic activity in the rumen $(50,51)$ and during the ensiling process (52).

Hydrolyzable tannins have often been regarded as potentially toxic, antinutritional plant secondary metabolites due to their tendency to be degraded in the rumen and absorbed by ruminants (53). More recently, however, potential benefits of HT on ruminant animal production systems have been reported (54-56). Unlike HT, CT have generally been considered as nondegradable by rumen microbes (57). However, possible ruminal degradation and total tract disappearance of CT have been reported. Robbins et al. (58) reported only $75 \%$ of CT consumed was recovered in feces of domestic sheep compared to $>90 \%$ recovery in mule deer. More recently, and using much more sophisticated measuring systems, Kronberg et al. (59) determined that more than $90 \%$ of the CT consumed by sheep were degraded. Conversely, Desrues et al. (60) recovered all CT from sainfoin following total tract passage through cattle. Like many biological activities driven by CT, degradation in the ruminant digestive tract is likely dependent upon plant species, tannin type, and chemical structure. The variation in the survival of CT through the digestive tract point to the need for the strategical application of CT (i.e., nutritional vs. antiparasitic effects, rumen vs. post-rumen activity, $\mathrm{CH}_{4}$ abatement vs. rumen protected $\mathrm{N}$ ) rather than the commonly used "shotgun" approach. The fate of $\mathrm{CT}$ in ruminants and associated nutritional implications should continue to be a future focus of research on physiological and modeling research (15).

\section{Ruminal Fermentation}

Polyphenolic phytochemicals potentially offer numerous benefits to ruminant animal production. The most notable of those benefits is rumen microbiome modifiers (61) to alter gaseous emissions (62) and improve animal production (63). Much of the recent research on tannins has focused on the topic of rumen modification to mitigate greenhouse gas emissions and improve the $\mathrm{N}$-use efficiency of ruminant livestock. The majority of this research has focused on the application of CT, but increased research interest in $\mathrm{HT}$ is becoming more evident.

Our knowledge and potential application of tannins in production scenarios are hindered due to a lack of understanding of how tannins interact with substrate and microbes in the rumen. Currently, $\mathrm{CT}$ are believed to reduce $\mathrm{CH}_{4}$ production in the rumen by combining three possible mechanisms (43): (1) the formation of CT complexes with fermentable macromolecules and microbial enzymes, reducing the availability of substrates to microbial degradation, (2) the direct interaction between microbes and $\mathrm{CT}$, resultant of $\mathrm{CT}$ binding to microbial lipopolysaccharide, and (3) CT subunits degrade in the rumen and become hydrogen sinks, reducing the hydrogen available to form $\mathrm{CH}_{4}$ gas. The hydrogen-sink hypothesis has been demonstrated with catechin monomer subunits in vitro by Becker et al. (64). However, tannin scientists have yet to reveal the possibility that $\mathrm{CT}$ polymers undergo the necessary degradation in the rumen to become hydrogen sinks. Similar to CT, HT is thought to reduce enteric $\mathrm{CH}_{4}$ by directly interacting with microbes or acting as a hydrogen sink (65). However, it is not believed that HT reduce $\mathrm{CH}_{4}$ by decreasing substrate availability as a concomitant decrease in $\mathrm{CH}_{4}$, and fiber digestion is typically not observed (66). However, our assumptions of how tannins behave in the rumen are continually evolving and require technological advancements and modeling techniques to understand the dynamic relationship better.

Recent research has focused on the application of respirometry methodologies to increase our understanding of the effects tannins have on $\mathrm{CH}_{4}$ emissions in vivo. However, in vivo research has been inconsistent, with discrepancies among $\mathrm{CT}$ and HT studies being indicative of complex associations. For example, the use of quebracho CT extract has resulted in reports of reduced $\mathrm{CH}_{4}$ emissions $(62,67)$ and no effect $(68)$. Of these studies, beneficial effects were observed in those that fed a roughage diet and higher rates of CT ( $>1.5 \% \mathrm{DM})$. This may be, at least in part, an effect of CT rate or diet type but is likely a combination of the two; however, we lack conclusive data to understand this complex relationship. Similarly, HT in ruminant diets has also demonstrated varied results for $\mathrm{CH}_{4}$ emissions. Recent work showed that gallic acid, an HT derivative, and tannic acid reduced $\mathrm{CH}_{4}$ emissions in beef cattle $(54,69)$, 
whereas HT from chestnut appears to have little or no effect (70). However, once again, we lack adequate data to conclude the reason for these differences. The discrepancies among CT and HT studies appear to point to a dynamic relationship among a variety of factors, including the chemical structure of the tannin, tannin inclusion rate, base diet (i.e., forage vs. concentrate), and animal species and stage of production (i.e., maintenance, growth, fattening, or lactation).

To garner a better understanding of the dynamic relationship among factors affecting tannin efficacy, in vitro gas production techniques have been used to screen tannin-rich forages for their potential to alter fermentation patterns and reduce $\mathrm{CH}_{4}$ emissions by ruminants. This approach has proven to be a costeffective and time-saving tool $(71,72)$. These techniques are especially useful when exploring domestication of wild types of perennial prairie legumes (73), investigating increased utilization of arboreal plant resources as forage (74), or when seeking the value of feeding invasive plant species to ruminants $(75,76)$. However, there is often some disparity between in vitro and in vivo $\mathrm{CH}_{4}$ production (77). To better understand the real impact of tannins on ruminant nutrition, long-term and conclusive in vivo or in situ studies must be conducted to calibrate in vitro data. We must enable the application of in vitro methods to provide a rapid determination of tannin feasibility in various production systems.

\section{Post-rumen Digestion}

Ruminant animals are generally considered inefficient at converting ingested protein into an animal product due to a large portion being lost as $\mathrm{NH}_{3}$ in the rumen. The efficiency of $\mathrm{N}$ use and retention by ruminants can be improved by either slowing the degradation rate of protein to enhance synchrony with carbohydrates or increasing rumen undegradable protein in the diet (78). Much of the interest in tannins revolve around the prospect of possible degradation and absorption of rumen undegradable protein following dissociation from tannin-protein complexes post-rumen. Condensed tannins readily decrease ruminal $\mathrm{N}$ digestibility (79), resulting in reduced urinary $\mathrm{N}$ excretion $(62,80)$ with a concomitant increase in fecal-N excretion and a possible reduction in excreta gas emissions (81). This shift in the site of $\mathrm{N}$ excretion might represent a decrease in $\mathrm{N}$ retention. However, some have reported increases in the efficiency of protein utilization expressed as weight gain per protein intake due to CT inclusion in the diet (82). Hydrolyzable tannins also bind and precipitate proteins, possibly increasing post-rumen availability of $\mathrm{N}$, but they also offer the potential to slow the ruminal degradation of $\mathrm{N}$ and possibly promote the synchrony of $\mathrm{N}$ and carbohydrate degradation. Much like what is observed when feeding CT to ruminants, a shift in N excretion from urine to feces is observed when including HT in the diet (56). While increases in $\mathrm{N}$ utilization associated with feeding HT have not been reported, supplementation with gallic acid may decrease urinary $\mathrm{N}$ excretion without negatively impacting $\mathrm{N}$ digestibility (54).

The ability to shift the route of $\mathrm{N}$ excretion from the urine to the feces without sacrificing $\mathrm{N}$ digestibility is increasing in interest due to excreta's contribution to total livestock emissions.
The feeding of CT has demonstrated the potential to decrease fecal gas emissions $(81,83)$ and reduce fecal urease activity (84). Similarly, nitrous oxide emissions from urine were reduced when gallic acid was fed (51). Once again, we lack adequate data to assume the mechanism(s) that alter emissions or that the observed alterations in excretion route and excreta emissions will improve overall emission status. However, based upon the positive results observed in the limited number of studies performed, research into the effect of tannins on excreta emissions warrants greater focus.

\section{Gastrointestinal Nematodes}

Gastrointestinal nematode (GIN) and other gastrointestinal parasite infections negatively impact ruminant nutrition. Both small and large ruminants are affected, but internal parasites are especially detrimental to small ruminants, including sheep and goats. Legume CT, particularly those from sericea lespedeza (Lespedeza juncea var. sericea), demonstrate anthelmintic activity against GIN parasites in small ruminants (85). Sericea lespedeza (Lespedeza cuneata) (86) and quebracho (Schinopsis sp.) (87) CT also inhibits Eimeria spp. in goats, which are responsible for coccidiosis. Condensed tannins may also be efficacious as an anthelmintic against common cattle parasites Cooperia oncophora and Ostertagia spp. (88).

Increased use of the larval exsheathment assay has led to the screening of novel forage CT for anthelmintic activity (89). In vitro screening for the potential anthelmintic activity of tannin-rich forages is not limited to CT. Concentrations of $25 \mathrm{mg}$ $\mathrm{HT} / \mathrm{ml}$ effectively kill Haemonchus contortus in vitro (55). Gallic acid reportedly demonstrates egg hatch inhibition against GIN that commonly infect cattle (90).

An important question that cannot be answered using in vitro techniques is what are the negative nutritional and toxic implications, if any, of feeding HT to ruminants for GIN control? Therefore, in vivo research must follow reports of positive impacts of CT but especially HT to confirm anthelmintic activity without detriment due to phytochemical toxicity. Some hypothesize that parasitized ruminants will intentionally select forages with anthelmintic properties (i.e., tannins). Some evidence of ruminant self-medication by selecting for tannin-rich forages when parasitized by GIN has been reported (91). More often than not, however, the self-medication hypothesis is not confirmed $(92,93)$.

\section{Why and When Do Tannins Work?}

The question of when and why tannins positively impact ruminant nutrition is a difficult one to answer. Tannin bioactivity, especially that of CT, is often plant-specific. The mechanisms of action for tannin biological activities, such as ruminal $\mathrm{CH}_{4}$ mitigation, reducing rumen proteolysis, or inhibiting GIN, are mostly unknown. The mechanism for one biological activity likely differs from that of another.

There is evidence that structurally recalcitrant tannins are most effective in modifying fermentation and reduce $\mathrm{CH}_{4}$. For example, CT from Acacia angustissima var. hirta are highly effective at reducing enteric $\mathrm{CH}_{4}$ production (73). The undegradable 5-deoxy flavan-3-ol structure of the Acacia CT 
likely contributes to its ability to mitigate $\mathrm{CH}_{4}$ formation during fermentation (94). Additionally, tannins' antioxidant activity is positively correlated $(r>0.90)$ to ruminal $\mathrm{CH}_{4}$ emission (94), suggesting that antioxidant activity at least contributes to the mechanism of action involved in CT- $\mathrm{CH}_{4}$ mitigation.

The ability of tannins to bind and precipitate protein, and potentially create rumen undegradable protein, may depend on factors associated with chemical structure and conformation, the $\mathrm{pH}$ in which the tannin-protein interaction occurs, and the herbivore's ability to bind tannins with salivary proteins during mastication and rumination. The structural diversity of tannins adds to the difficulty of determining the impact of specific structural characteristics on tannin-protein interactions. Structural attributes of CT, including the mean degree of polymerization, stereochemistry, and prodelphinidin-to-procyanidin ratio, sometimes do not explain protein-tannin interactions (95). However, some reports suggest that large prodelphinidin-based CT demonstrate greater protein precipitating capacity than large procyanidin-based CT (96). Recently, the impact of the increased mean degree of polymerization and inter-flavan bond type on protein precipitation capacity has been confirmed (97). Similar to factors affecting protein precipitation by CT, larger polymers of HT demonstrate greater protein precipitating capacity than monomeric forms (98).

The $\mathrm{pH}$ is an important factor affecting the protein precipitating capacity of tannins; the closer to the isoelectric point of the protein, the greater the protein precipitation capacity $(99,100)$. Much of what we know about the role of $\mathrm{pH}$ in CT-protein interactions supports the hypothesis that protein-tannin complexes dissociate in acidic environments (such as in the abomasum of ruminants), leading to protein degradation and subsequent amino acid absorption in the small intestine. As the $\mathrm{pH}$ of the environment where tanninprotein complexes occur becomes more acidic relative to the isoelectric point of the protein, the protein precipitating capacity of tannins decreases (100). Accordingly, when the environment is less than $\mathrm{pH} 5$, tannin-protein complexation may be minimal (101).

The neutralizing effect of proline-rich protein in saliva has long-been hypothesized (102). Many browsing herbivores that readily consume tannins do not produce saliva that contains proline (103). Despite a lack of proline, some browsing ruminants (i.e., goats) can bind tannins with salivary proteins (104), suggesting that proline is not a requisite for all salivary proteintannin interactions.

An explanation for when and why tannins are useful anthelmintics continues to be elusive. Much of the literature suggests the efficacy of both CT and HT against GIN is dose-dependent $(55,89)$, such that greater concentrations of tannin result in more significant anthelmintic effects. Tannin concentrations vary within species based on plant maturity, which is another factor to consider. In some species, mature plants produce lower tannin concentrations than immature plants $(76,105)$, whereas others may increase or remain unchanged with maturity (105). However, it is crucial to fully understand the CT concentration at different seasonal growth stages in a given plant species (106) to maximize their ontogenic phytochemical characteristics on sustainable ruminant production systems (8).

\section{Why Do Tannins Not Work?}

Dietary tannins do not always affect the nutritional status of the ruminant animal. There are many possible reasons for this. If the forage or feed resource is too low in tannin concentration, little, if any nutritional impact will be observed. The tannin's chemical structure produced by a given plant can determine whether or not the phytochemical is effective at eliciting a desired animal response. Modes of action of tannins also differ for different activities such that the type and structure of tannin used to elicit one nutritional response may not be useful for that of another. Another challenge occurs when feeding highly bioactive tannin-rich forages. The animal may reject tannin-rich forage due to reduced palatability due to salivary protein binding and astringency.

\section{Future Perspectives}

There is still much to learn about how CT and HT affect ruminant animal nutrition. Much of what we understand about tannin impacts on ruminant nutrition is the result of in vitro studies. While in vitro assays are excellent screening tools, more in vivo confirmation of research findings is needed to move tannin science from use-inspired basic research to application. A significant challenge to this progress is the lack of domesticated (cultivated) plants rich in bioactive tannins. As a result, the availability of plant material suited for many ruminant producing regions is limited. Even when the seed is commercially available, it is often cost-prohibitive due to the limited supply and labor required to collect undomesticated species.

Future research should emphasize the strategical application of tannins rather than the current "shotgun" approach from a nutritional perspective. Much of the previous and recent research has emphasized directly inhibiting enteric $\mathrm{CH}_{4}$ production and increasing rumen undegradable protein. However, there is potential to utilize some tannins' degradation to reduce $\mathrm{CH}_{4}$ via hydrogen-sink and increase $\mathrm{N}$-use efficiency by improving nutrient synchrony. There are opportunities to exploit tannins' antioxidant properties, particularly immunomodulatory effects, thermal stress, and human-health products. Tannins' influence on excreta emissions requires attention, but ultimately we need to understand better how excreta from animals consuming tannins alters soil fertility, soil microbiota, and plant growth.

Despite deficiencies in current knowledge about nutritional implications in ruminant animals, polyphenolic phytochemicals (i.e., tannins) have great potential as a tool in ruminant production systems. Further investment in plant breeding and domestication efforts, as well as research efforts to further elucidate how tannins impact ruminant nutrition and system processes, will be necessary to realize the full potential of these important phytochemicals. 


\section{TERPENES}

\section{Biosynthesis and Functionality}

The bitter-taste, emulsifying, foaming, non-ionic, nonvolatile, membranolytic, surfactant, and structurally diverse saponins (glycosides) are low molecular weight $(1,000-1,500$ Da) secondary natural compounds in food and non-food plants (107-109), marine plants (110) and animal lineages, including invertebrate sea cucumber species $(111,112)$. Chemically, glycoside saponin biosynthesis begins with the catalyzation of acetyl co-enzyme A to isopentenyl pyrophosphate units generated by the multistep mevalonate 3-hydroxy-3methylglutaryl-CoA reductase (113), a common route to the synthesis of cholesterol and some steroids (114).

Saponins comprise the hydrophobic aglycone (sapogenin) structure that is linked to polar functional groups and attached via a 3-C chain structure to an individual or multiple hydrophilic sugars (i.e., arabinose, galactose, glucose, glucuronic acid, methylpentose, rhamnose, or xylose) $(115,116)$ and moieties (i.e., glycones) $(117,118)$. Aglycones are subject to gene encode enzyme-mediated (i.e., cytochrome P450dependent glycosyltransferases, monooxygenases, and others) (119) change (i.e., acylation, hydroxylation, glycosylation, oxidation, and substitution) $(119,120)$ to form a varied group of compounds (121).

Saponins are chemically categorized into two groups: triterpene or steroidal. Following the isoprenoid pathway, the aglycone splits into pentacyclic triterpenoid saponins (TPS) with a 30-C aglycone core by cyclization of 2,3-oxidosqualene (113, $117,122)$, yielding the first group of saponins. The second group is related to the biosynthetic pathway of tetracyclic steroidal metabolites to a $27-\mathrm{C}$ aglycone backbone $(114,117,120)$ with a 5-ring furostane or a 6-ring spirostane skeleton (123) involving oxygenations and glycosylations (117).

Although in the presence of other phytochemistry (124), saponin mixture in a single plant species occurs $(120,121$, 125), such as cucurbitane, cycloartane, dammarane, holostane, hopane, lanostane, lupane, oleanane, tirucallane, taraxastane, tirucallane, and ursane TPS types $(107,126)$ have been identified in more than 500 plant species (114). Within a hundred familygroup plants, the Anacardiaceae, Araliaceae, Combretaceae, Compositae Campunalaceae, Caryophyllaceae, Leguminosae, Polygalacea, Sapindaceae, Theaceae, and Verbenaceae families, their genera and species attract more attention (114, 127-131).

In angiosperm monocotyledons and angiosperm dicotyledons plants, the variation, composition, concentration, distribution, and differential bio-activity of TPS are influenced by plant growth, agronomic and genotype-environmental interactions (132-134). Moreover, TPS-plant storage, physical milling, TPS separation, and the bio-accessibility of metabolites in the form of concentrated extracts, derivatives, or food additives to facilitate human-animal utilization may modify aglycones' structure and their bio-physiological, nutraceutical, and pharmaceutical activities (121, 124, 135).

Although paths for those roles are not well-understood and despite differences in chemical structures, different activities exist for TPS, including adjuvant (136), antibacterial (137,
138), antidiabetic (139), antifungal (140-142), anti-inflammatory (123, 125), antioxidative $(109,143)$, antiprotozoal (144-146), antiproliferative (147), antiviral $(148,149)$, cardiotonic and cardioprotective (122), and cytotoxic $(127,128,150)$ effects have been reported. Additionally, TPS have also exhibited other functional properties, such as food-additive in flavorings (26), gastroprotective $(151,152)$, hemolytic $(153)$, hepatic $(139,149)$, immunologic $(123,154)$, insecticide $(155,156)$, anti-obesity therapeutic potential $(111,116,157,158)$, neuroprotective (159), vermicide (160), and emulsifier and stabilizer of the nanosuspensions $(161,162)$.

\section{Nutritional Importance}

Central to TPS's bio-physicochemical network of interactions, the nutritional significance of TPS for ruminants stems largely from their digestive and methanogenic significance (163). Consequently, using Medicago sativa L. (alfalfa) and C. sinensis L. (tea plant) as examples, this review will be limited to considering certain aspects of the bio-metabolic and rumen microbial shifts in sheep and cattle derived from TPS supplementation, which are not entirely consistent and understood. Compared to nonsupplemented diets, Table 1 has a comparative overview of digestive function reaction to alfalfa-TPS $(26.9-601.3 \mathrm{mg} / \mathrm{g}$ extract) intraruminal or feed-mixed supplemented [10.6-800 mg TPS/kg body weight $(\mathbf{B W})$ ] in different breeds and BW $(42-60 \mathrm{~kg})$ of sheep between 14 and 90 days.

Based on the use of $17.8-35.9 \mathrm{mg}$ TPS/g extract, an intraruminal increasing TPS-dose in wethers fed roughage diets resulted in a less disturbed digestive system than the digestive responses of intraruminal supplemented wethers fed concentrate diets (164). However, using $27.8 \mathrm{mg}$ TPS/g extract, compared to the lowest intraruminal dose of $200 \mathrm{mg} / \mathrm{kg}$ BW in Suffolk wethers fed grass-hay, $800 \mathrm{mg} / \mathrm{kg}$ BW administered intraruminally increased rumen pressure, particulate matter outflow, and VFA concentration by 25,25 , and $10 \%$, respectively (115). This effect was further associated with a reduction in organic matter $(11 \%)$ and neutral detergent fiber (10\%) total tract digestibilities, ciliate protozoa populations (CPP; $80 \%)$, and daily $\mathrm{CH}_{4}$ production (8\%) (115).

There is limited experimental data on the use of TPS on animal production under mid to long-term management. However, Liu et al. (108) demonstrated complementary opportunities for both physio-metabolism and production evaluation. These authors indicated that a high-TPS concentration extract shifted from 0.04 to 0.08 TPS-to-dry matter intake (DMI) ratio in concentrate plus roughage diets used by $\mathrm{Hu}$ male-lambs during 90 days, yielded a 12, 44, 2, 2, and 7\% increase in dry matter (DM), neutral and acid detergent fibers, ether extract, and crude protein digestibilities, respectively. Nevertheless, when the TPS supplementation increased from 24 to $94.3 \mathrm{mg} / \mathrm{kg}$ BW, the effects on DM, neutral and acid detergent fibers, ether extract, and crude protein digestibility decreased by $12,44,2,2$, and $7 \%$, respectively. These effects were also associated with an $8 \%$ reduction in daily BW gains.

These studies illustrate how sheep responses can be influenced by motivated, focused action. However, the long-range vision 
TABLE 1 | Effects of triterpenoid saponin (TPS) supplementation on several ruminal and total gastrointestinal tract parameters ${ }^{1}$.

\begin{tabular}{|c|c|c|c|c|c|c|c|c|c|c|c|c|c|}
\hline \multirow[t]{2}{*}{ Plant species ${ }^{2}$} & \multicolumn{5}{|c|}{ TPS-animal interaction } & \multicolumn{8}{|c|}{ Digestive parameters } \\
\hline & Extract & TPSC & Animal & $\mathrm{mg} / \mathrm{kg} \mathrm{BW}$ & TPS:DMI & $\mathbf{R M}$ & RPC & PMO & OMD & NDFD & TVFA & CPP & DMP \\
\hline \multirow[t]{4}{*}{ Medicago sativa L. ${ }^{a}$} & Root & 27.8 & Sheep ${ }^{\ddagger T}$ & 200 & 1 & 1.74 & +22 & 0 & -1 & -2 & +6 & -42 & +6 \\
\hline & & & & 400 & 2 & 1.67 & +21 & +4 & -7 & -8 & +3 & -81 & +5 \\
\hline & & & & 800 & 3 & 1.67 & +53 & +25 & -12 & -12 & +17 & -88 & -2 \\
\hline & & & & & TPS:DM & RTR & TMRT & DMD & OMD & HEMD & CELD & TVFA & CPP \\
\hline \multirow[t]{5}{*}{ M. sativa } & Plant & 26.9 & Sheep $^{\dagger}$ & $10.6^{*}$ & 2 & -6 & 0 & -1 & -1 & -2 & -6 & +1 & -37 \\
\hline & & & & $21.4^{*}$ & 4 & -3 & -2 & 0 & 0 & -1 & +4 & -6 & -47 \\
\hline & & & & 10.6 & 2 & -24 & +10 & +6 & +1 & +35 & +32 & -19 & -33 \\
\hline & & & & 21.4 & 4 & -23 & +7 & +9 & +2 & +28 & +40 & -28 & -55 \\
\hline & & & & & TPS:DMI & & & DMD & NDFD & ADFD & EED & CPD & \\
\hline \multirow[t]{4}{*}{ M. sativa ${ }^{c}$} & Leaf-root & 601.3 & Sheep & 12.0 & 0.04 & & & -1 & -15 & +15 & 0 & +2 & \\
\hline & & & & 24.0 & 0.08 & & & +11 & +22 & +17 & +2 & +9 & \\
\hline & & & & 47.1 & 0.16 & & & +4 & +1 & -24 & -2 & +3 & \\
\hline & & & & 94.3 & 0.32 & & & -3 & -8 & -15 & -5 & -4 & \\
\hline
\end{tabular}

${ }^{1}$ Ratios of TPS to dry matter (DM) (TPS:DM) or TPS to DM intake (DMI) (TPS:DMI); rumen motility (RM, $n /$ min) ${ }^{\dagger}$; rumen pressure change (RPC, mm Hg) ${ }^{\dagger}$; ruminal turnover rate (RTR, \%/h); total mean retention time (TMRT, h); particulate matter outflow (PMO, g/d); total-tract crude protein (CP), DM, ether extract (EE), organic matter (OM), neutral detergent fiber (NDF), acid detergent fiber (ADF), hemicellulose (HEC), and cellulose (CEL) digestibilities (g/100 g); total volatile fatty acids (TVFA, $\mathrm{mmol} / \mathrm{L})$; ciliate protozoal populations ( $\left.{ }^{\ddagger} \mathrm{CPP} \times 10^{5} / \mathrm{ml}\right)$; and daily methane production (DMP). The notations + refers to an increase and - refers to a decrease in percentage values relative to non-TPS supplemented diets data in each experiment. Triterpenoid saponin concentration (TPSC) is presented in $\mathrm{mg} / \mathrm{g}$ of M. sativa plant extract; and $\mathrm{mg} / \mathrm{kg}$ DM of M. sativa root extract, and M. sativa leaf-root commercial extract product. ${ }^{2} \mathrm{a}=$ Klita et al. (115) in which intraruminal TPS extract supplementation was conducted for 14 days. ${ }^{\dagger}$ Measured on day $11 .{ }^{\top}$ Methane measurements (24 h) on day 12 based on indirect calorimetry and respiratory hoods from 4 Suffolk wethers. $b=L u$ and Jorgensen (164) in which *roughage and ${ }^{*}$ concentrate diets fed to wethers subject to intraruminal daily

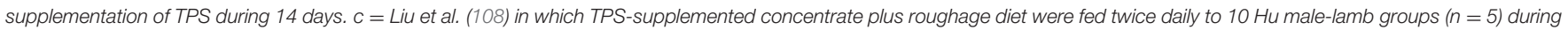
90 days.

to shape or reshape TPS's use and ensure its relevance to small ruminant needs a particular combination of knowledge and perspectives. It should equate the sheep feed industry interest with clinical science in the context of a deepening sense of animal practice responsibilities to concomitantly address societal needs and ecosystem environmental challenges.

Overall, we can only speculate that the TPS-extract source within the same plant species, the extraction method, compound composition, concentration and dose, way and time of supplementation, diet type, and sheep genetics refer to the range of variation in the summarized alfalfa-TPS supplementation response in Table 1. Unless such information is forthcoming, there is a risk of limiting factors to benefit from the TPS functional activities described above with sheep if they are susceptible to specific doses in farming grazing conditions.

Table 2 illustrates how cattle and sheep respond to TPS supplementation. It illustrates the impact of TPS doses from tea seeds and alfalfa extract sources on fermentative, microbial, and blood parameters of Brahman (Bos indicus) and crossbred B. indicus cattle $(234-364 \mathrm{~kg})$ and sheep $(41.7-42.5 \mathrm{~kg})$. The approach is justifiable because, in the current and post-COVID challenges, it is unlikely that individual research could undertake simultaneous cattle-sheep TPS supplementation assessments. However, it would be possible for cooperative research across the livestock industry to justify the expense involving additional knowledge gains.

As with beef cattle, sheep can cope with increasing doses of tea seed-TPS. A difference is the range of TPS doses tested between large and small ruminants. Another critical difference is the greater emphasis on cattle measurements after TPS withdrawal than on sheep. This has resulted in the interaction among supplementation digestive and fermentative parameters. The summarized data indicate that Ramos-Morales et al. (169) pointed out that TPS does not always reduce CPP. However, this information may not be surprising because saponin functional diversity and biological pathways do not always positively correlate (170). Early on, Dourmashkin et al. (171) provided evidence that saponins at $0.05 \%$ concentration modify eukaryotic cell membrane permeability by producing a pore-forming characteristic expected to inhibit both CPP (115) and $\mathrm{CH}_{4}$ emissions (172).

Published trials using tea seed-TPS indicated that their anti-methanogenic effect in vitro (173) in small ruminants $(167,168,174)$ is considered to be a selective saponin-sterol association $(175,176)$ on protozoa surface $(170)$. Nevertheless, CPP may increase when plant-TPS $(145,177)$ and low cell-wall carbohydrate diets are fed (178).

Dourmashkin et al. (171) found that saponin-treated cell membrane growth is associated with concentrations above $0.09 \%$. Sidhu and Oakenfull (179) also demonstrated that, when orally fed, saponins are not absorbed into the bloodstream but might modulate mitosis $(180,181)$ by molecule transport, cell membrane fluidity, and cell proliferation in vitro (182) and in vivo (183).

Contrary to the transient antiprotozoal effect of TPS (184), a linear increase of protozoal numbers is triggered by increasing tea seed-TPS doses in crossbred Brahman cattle, while a defaunation effect was observed at 13 days post-TPS treatment 
TABLE 2 | The effects of supplementing triterpenoid saponin (TPS) from Camellia sinensis L. or Medicago sativa L. on digestive and blood profiles of ${ }^{\dagger}$ Belmont Red Composite [Africander (African Sanga) $\times$ Brahman (Bos indicus) $\times$ Hereford-Shorthorn (3/4 B. taurus)] and *Brahman steers, and $¥$ Dorper crossbred $\times$ thin-tailed Han ewes, ${ }^{\dagger}$ Hu rams, ${ }^{\mathrm{T}}$ Huzhou lambs and ${ }^{*} \mathrm{Hu}$ male-lambs ${ }^{\mathrm{a}}$.

\begin{tabular}{|c|c|c|c|c|c|c|c|c|c|c|c|c|}
\hline \multirow{3}{*}{$\begin{array}{l}\text { Parameters }^{\text {b, c }} \\
\text { TPS mg/kg BW }\end{array}$} & \multicolumn{12}{|c|}{ C. sinensis ${ }^{\mathrm{b}, \mathrm{c}}$} \\
\hline & \multicolumn{5}{|c|}{ Cattle $^{\dagger}$} & \multicolumn{2}{|c|}{ Sheep $^{\ddagger}$} & \multicolumn{3}{|c|}{ Sheep ${ }^{t}$} & \multicolumn{2}{|c|}{ Sheep ${ }^{T}$} \\
\hline & 31.5 & 44.3 & \multicolumn{3}{|c|}{ Post-TPS } & \multicolumn{2}{|c|}{28.6} & \multicolumn{3}{|c|}{83.7} & \multicolumn{2}{|c|}{112} \\
\hline TPS:DMl & 0.14 & 0.22 & \multicolumn{3}{|c|}{ Post-TPS } & \multicolumn{2}{|c|}{0.13} & \multicolumn{3}{|c|}{0.18} & \multicolumn{2}{|c|}{0.30} \\
\hline TVFA & +3 & -2 & \multicolumn{3}{|c|}{-2} & \multicolumn{2}{|c|}{+16} & \multicolumn{3}{|c|}{-3} & \multicolumn{2}{|c|}{+13} \\
\hline CPP & +99 & +190 & \multicolumn{3}{|c|}{-5} & \multicolumn{2}{|c|}{-16} & \multicolumn{3}{|c|}{-42} & \multicolumn{2}{|c|}{-41} \\
\hline DMP & +6 & +3 & \multicolumn{3}{|c|}{-16} & \multicolumn{2}{|c|}{+2} & \multicolumn{3}{|c|}{-11} & \multicolumn{2}{|c|}{-27} \\
\hline \multirow[t]{2}{*}{ Animal species } & \multicolumn{12}{|c|}{ C. sinensis serum biochemistry } \\
\hline & TPS mg/kg BW & TPS:DMI & CL & $\mathbf{K}$ & Na:K & $\mathbf{I}$ & GLU & $\mathrm{CHO}$ & UM & GGT & ALP & AST \\
\hline \multirow[t]{5}{*}{ Cattle } & 22.7 & 0.11 & -1 & -12 & +12 & -23 & -15 & +5 & -29 & +5 & +5 & -5 \\
\hline & 44.2 & 0.21 & +1 & -11 & +12 & -21 & -15 & 0 & -17 & +10 & +10 & -7 \\
\hline & 64.9 & 0.30 & +3 & -12 & +13 & -22 & +3 & +5 & -20 & +17 & +17 & 0 \\
\hline & \multicolumn{12}{|c|}{ M. sativa plasma profile } \\
\hline & & & GH & IGF-1 & T3 & T4 & GLU & $\mathrm{CHO}$ & UN & TRG & ALT & AST \\
\hline \multirow[t]{4}{*}{ Sheep* } & 12.0 & 0.04 & +38 & +32 & +77 & +42 & +20 & +2 & +5 & -2 & +46 & +31 \\
\hline & 24.0 & 0.08 & -9 & -5 & +22 & -9 & +16 & -7 & -30 & -35 & +49 & +27 \\
\hline & 47.1 & 0.16 & +8 & +2 & +11 & -18 & +20 & -9 & -44 & -68 & +81 & -27 \\
\hline & 94.3 & 0.32 & +5 & -8 & +40 & +4 & +21 & -3 & -35 & +3 & +98 & -28 \\
\hline
\end{tabular}

a Positive and negative percentage data refer to non-TPS supplemented diets in each experiment.

${ }^{b}$ Ciliate protozoal populations ( ${ }^{+} \mathrm{CPP} \log \times 10^{8} / \mathrm{ml}$ rumen fluid, ${ }^{\mathrm{T}} \mathrm{CPP}$ a \% of total bacterial $16 \mathrm{~S}$ rDNA, ${ }^{\dagger} \mathrm{CCP} \times 10^{5} / \mathrm{ml}$, $\left.{ }^{\ddagger} \mathrm{CCP} \times 10^{7} / \mathrm{ml}\right)$, daily methane $\left(\mathrm{CH} \mathrm{H}_{4}\right)$ production $(\mathrm{DMP})$, dry matter intake (DMI), body weight (BW), total volatile fatty acids (TVFA, mmol/L). Serum electrolytes and minerals [mmol/L; chloride (CL), potassium (K), sodium to potassium ratio (Na:K), iron (I, $\mu \mathrm{ml} / \mathrm{L})]$. Metabolites [mm//L; cholesterol (CHO), glucose (GLU)]. Renal function [mmol/L; urea nitrogen (UN)]. Enzimes [IU/L; alkaline phosphatase (ALP), aspartate aminotransferase (AST), $\gamma$-glutamyl transferase (GGT)]. Plasma hormones [ng/mL; growth hormone (GH), insulin-like growth factor-1 (IGF-1); mmol/L; tri-iodothyronine (T3), and thyroxine (T4)]. Metabolites [mg/dL; urea nitrogen (UN), glucose (GLU); mmol/L; triglyceride (TRG), alanine transaminase (ALT), aspartate aminotransferase (AST)].

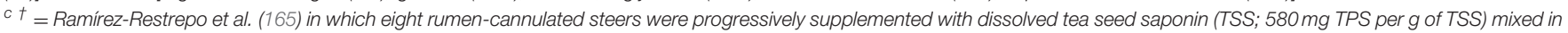
the morning diet during 3 and 4 days. Post-TPS values were recorded 13 days after TPS withdrawal. Individual $\mathrm{CH}_{4}$ emissions were measured (48 h) in open-circuit respiratory chambers, recording levels of supplementation of 27.0 and $43.5 \mathrm{mg} \mathrm{TPS} / \mathrm{kg} \mathrm{BW}$, which are equivalent to ratios of 0.13 and 0.23 TTS:DMI, respectively. ${ }^{+}=$Ramirez-Restrepo et al. (166) in which

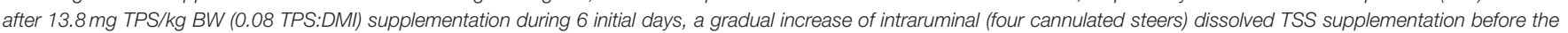

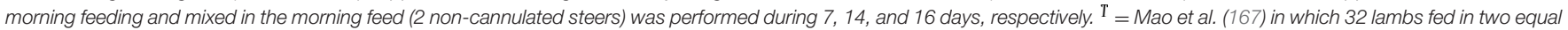

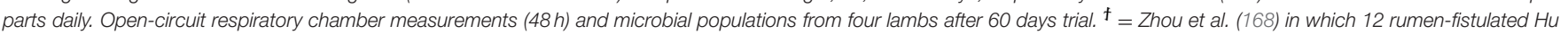

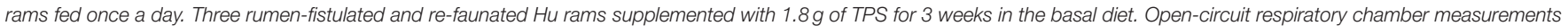

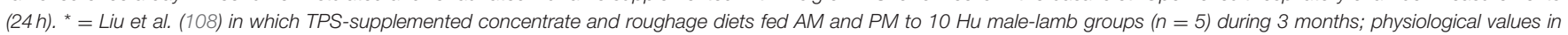

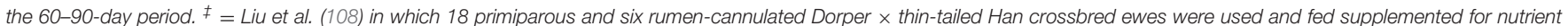
digestibility and $\mathrm{CH}_{4}$ emissions in open-circuit respiratory systems (Experiment 1, 29 days), and fermentation and microbial ecology examination (Experiment 2, 42 days), respectively.

as shown in Table 2 (165). There, TPS modified the structure of the methanogen community at the subgenus by increasing the numbers of methanogens and decreasing their abundance in the RO and SGMT clades, respectively (185). In parallel, TPS supplementation reduced numbers of protozoal genus Entodinium spp. and increased Euplodinium and Polyplastron genera. The withdraw of TPS supplementation was associated with lower proportions of Isotricha and the greater presence of Metadinium and Eudiplodinium genus (185).

This suggests that, in tropical cattle, TPS may have a high selectivity index for protozoa, without an adaptation of those ciliates and other microbial communities to short-term feeding of TPS. Moreover, it is essential to note that tea seed-TPS as a feed additive appears to exert a differential protozoal and anti-methanogenic effect across Dorper $\times$ thin-tailed Han crossbred ewes, Hu rams, and Huzhou lambs (Table 2). With these facts in mind, readers are directed to $\mathrm{Hu}$ et al. (173), Guo et al. (172), Mao et al. (167), Zhou et al. (168), Wang et al. (186), and Liu et al. (187) for the detailed complementary impact of TPS on rumen ecology and extend of nutrient digestion. Together, these findings mirror the belief that further research is required to understand better multifaceted TPS supplementation effects associated with the breed, sex, and animal category sound interactions.

\section{Future Perspectives}

Although in our research no comparison of patterns of $\mathrm{CH}_{4}$ emissions was performed between a single and two equal daily portions of TPS supplementation, there is little doubt that the circadian rhythm of $\mathrm{CH}_{4}$ emissions from steers after the morning non-supplemented and TPS-supplemented diets (165) is consistent with that observed in twice-daily TPS-supplemented 
sheep $(167,168,188)$ and cattle fed Rhodes grass (Chloris gayana Kunth) ad libitum (189). Conversely, the current review provides evidence that forage diets fed to ruminants could modulate the animal response to TPS-sources inclusion in tropical agriculture (177, 190-192). However, this reason may be further explained by capturing TPS supplementation advantages in seasonal nutrition, fermentability, and methanogenic indices of forages $(71,72)$. A sustainable ruminant industry should consider three questions. How long does the TPS-protozoal selective effect in the rumen ecosystem of tropical cattle last? Is this physio-metabolic response opening the possibility that tea seed-TPS may reduce cattle $\mathrm{CH}_{4}$ emissions in the longterm rather than as an immediate abatement? Should we investigate the effects of very low TPS concentration additives and/or far lower TPS:DM ratios on ruminants to achieve target microbial community profiles without significant associated meta-physiological disturbances?

Few ruminant studies beyond methanogenesis have focused on complementary clinical responses to TPS supplementation (Tables 1, 2) to understand or confirm pharmacological discoveries, phytochemical screening, safety, and efficiency of therapies, and in vitro findings. In particular, safety and tolerability studies have demonstrated that Brahman (166) and Belmont Red Composite [Africander (African Sanga) $\times$ Brahman $\times$ Hereford-Shorthorn (3/4 B. taurus)] (165) steers tolerate on average $32.2 \pm 16.61$ and $27.3 \pm 13.53$ $\mathrm{mg} / \mathrm{kg}$ BW of TPS supplementation during 23 and 20 days, respectively. This for each breed is $\sim 6.4$ and 4.5 vs. 5.5 and 3.8-fold the non-toxicological effect levels in mice (i.e., subcutaneous injection) (117) and dogs (i.e., intramuscular route) (193), respectively.

However, as low TPS doses in Brahman $(13.8 \pm 0.64 \mathrm{mg} / \mathrm{kg}$ BW) and Belmont Red Composite $(9.2 \pm 0.35 \mathrm{mg} / \mathrm{kg} \mathrm{BW})$ steers are 1.9 and $1.2 \%$; respectively, of the canines long-term daily administration (i.e., 26 weeks), this variation might facilitate further efforts to clarify biological constraints and a vision of improved farming practices. In parallel, TPS effects on animal behavior and health indicated that the administration at $0.42 \pm$ $0.013 \%$ of the DMI to Brahman steers remarkable reduced DMI, and developed primary tympany and enteritis.

Although that high dose was not tested on Belmont Red Composite steers, a similar clinical pattern of symptoms but a lower magnitude were experienced when TPS doses achieved between 0.10 and $0.14 \pm 0.003 \%$ on the DMI. This was consistent with other studies $(194,195)$ that reported that some TPS might disrupt endothelial permeability, infiltration of cellular systems, and active nutrient transport, and nutrient uptake in the gut. This likely involves a sequential cascade involving cytokines, chemokines, reactive oxygen species expressions, and several intracellular signaling pathways, to name a few (196). However, those cattle dose-dependent effects contrast Klita's et al. (115) reports that sheep have a lethargic feeding behavior and lack of rumination associated with intra-ruminal TPS:DMI ratios of 4 and $8 \%$.
The interaction between TPS and the functional capacity of organs and body systems can produce relatively complicated outcomes. Table 2 underpins blood test differentiation between TPS-plant sources and animal species. That strategy should, in turn, allow greater understanding of significant differences in blood biochemistry and biological drivers between noncannulated and cannulated cattle after TPS supplementation (166). Based on the evidence provided here, it appears that such physiological associations could be the vehicle to spread knowledge and refine and collect prolonged assessments to ensure practical use of TPS additives.

Collectively, in response to the natural structure of TPS and their related sapogenins $(126,169,170,184)$, possible reasons for the observed differences within bovids are the pharmacodynamic and pharmacokinetic profile expressions of the host physiological system (197, 198). This is likely characterized in healthy animals by differential genetic and metabolic binding, interindividual variability, cellular and molecular self-regulatory feedback mechanisms, induction and inhibition of pathways, pharmaco-genomics, and pharmaco-metabolomics (199).

However, supported by the heterogeneity of systemic reactions shown in Tables 1, 2, it is suggested that a broad medical approach in future studies is critical to understanding TPS supplementation throughout the interrelationships within and between ruminant species, breeds, and crossbred animals. Medicine will benefit from increased knowledge of more significant or down-regulation expression of signal transducers, transcription factors, membrane proteins, ion channels, and mitochondrial enzymes in cell lines (200, 201). Such observations further indicate the relevance of complementary microbiota analysis to understand the impact on ruminal ecology, methanogenesis, and animal physiological functioning following clinical-relevant TSS-supplementation and at withdrawal endpoints.

In summary, although over the last years, review research advances in TPS have been evident $(27,162,202-$ 208), the disparities in physicochemical characteristics of close and non-closely intermediate related compounds in TPS-containing plants (209-211) from one to another material depends on the vast structural diversity of TPS molecules $(131,212)$. Therefore, feasible investigations should focus on TPS physio-metabolic interactions after ingestion to elucidate complex interactions with the diet's nutritive value and substantial variation in gastrointestinal microflora and animal metabolisms. This is reasonably straightforward in intermolecular forces, genetic-molecular animal predispositions, cellular signaling frameworks, intracellular-matric chemoreceptors, metabolic fluxes, multi-enzyme cascade, and morphological changes. The approach across the catalog of TPS-plants, their phytochemical compounds, and interactions will promote secondary compound-physiologicalbased ruminant models (15), human and animal health, regulatory environments, ecosystems management, and eco-efficient ruminant production. 


\section{VITAMINS AND ANTIOXIDANTS}

\section{Types of Vitamins}

Various vitamins and related minerals, many of which play critical roles as antioxidants important for growth and health, are sometimes deficient in ruminant diets. Ruminant requirements change with species, class, age, weight, health, and growth performance (213), but much of the research into these requirements are outdated and not representative of current production systems. Vitamin and related mineral deficiencies most often affect animals fed in confinement and only rarely occur in those allowed to graze or browse pastures and rangeland containing abundant, diverse plant species except when soils are severely deficient, as is sometimes the case with Se (214). When deficiencies occur, they are often a result of incorrect ration formulations or antagonistic effects (e.g., $\mathrm{K}$ and $\mathrm{P}, \mathrm{S}$, and $\mathrm{Cu}$ ). However, they can be corrected by supplementation, feed changes, or allowing animals access to diverse pastures containing dicotyledenous species, such as legumes. Historically, cattle confined feeding operations have supplemented ruminants at or above published requirements as a preventative measure (215).

In grazing or browsing ruminants, most vitamins and minerals necessary in cellular antioxidant activity can be ingested from fresh plant material. In turn, these are transferred to ruminant products; dairy products especially can accumulate these compounds, often quantified as antioxidant protection degree (214) or total antioxidant capacity (216). Unsaturated fatty acids, phenols, and volatile compounds are likewise transferred from forages to dairy products and play important roles in taste and odor as well as eventual consumer health (217). These are incredibly rich in grazing systems, at times ten times greater than in stall-fed ruminant diets (218). Therefore, vitamin and mineral supplementation often becomes the best management option only in confined feeding operations or monoculture grazing systems.

\section{Importance}

The $\alpha$-tocopherol and related compounds (vitamin E) and closely associated selenium (Se) are common feed-related deficiencies in confined ruminants not fed fresh green forages (219). Both are important in antioxidation processes that mitigate stress. Vitamin E, in conjunction with Se, plays a crucial role in cellular antioxidation. When deficient, physiological and immunological functions can be impaired, as can growth performance in confinement (220).

Retinol (vitamin A) is fat-soluble and plays an important role in ruminant eyesight, bone development, epithelial cell function, reproduction, as well as general immune functions (221). In ruminants, retinol enhances antioxidation that protects against cellular free-radicals (222). Carotenes are retinol precursors, and, under pasture or rangeland conditions, over 10 carotenoids have been documented in forages that can meet ruminant requirements (221). Their presence in milk produces distinctive butter and cheese colors that consumers identify with grazingbased dairy. However, feeding trials in confined feeding systems where fresh, green forage was lacking indicate that retinol supplementation to sheep (223) and calves (224) increases its presence in animal tissue, indicating that deficiencies may occur. There is also evidence that Vitamin A can interfere with Vitamin E retention in ruminant blood plasma, liver, and fat tissue.

Ascorbic acid (vitamin C) inhibits cortisol release, is a robust cellular antioxidant, and plays a vital role in ruminant products' fatty acid profile, especially dairy (225). Its supplementation to confined ewes, for example, increases the antioxidant concentration in milk (226). It also affects lamb, but not kid, meat quality parameters when administered before transport and slaughter (227). Diet can be a strong determinant of herbivore blood and milk ascorbic acid concentrations (228, 229), and its injection in confined cattle can reduce mortality rates (230).

Folic acid and vitamin $\mathrm{B}_{12}$ supplemented to confined multiparous (older) dairy cows can reduce dystocia by $50 \%$ and speed up first breeding postpartum by 3.8 days (231). It has no effect on primiparous dairy cows or any other health or reproductive factor for either class of animals. This indicates that, in confined feeding conditions, these can be essential supplements in multiparous ruminants where vitamin B can become depleted over time. No similar positive effect of folic acid and vitamin $B_{12}$ supplement in pastured ruminants has been observed.

\section{The Ruminant Animal's Perspective}

Stress on ruminants affects animal health by increasing cellular oxidation. Stresses include abiotic factors, such as climate (mainly temperature extremes) or management, including transport or handling (219). Biotic stresses include interaction with other animals, reproduction, lactation, and feed quantity and quality deficiencies, as well as numerous other potential interactions with the living environment. Oxidative stress occurs when reactive oxygen species or free radicals surpasses the detoxification capacity of antioxidants. Activation of inflammatory-immune response and decreased overall immune function can result. There is evidence indicating that oxidative stress during weaning and transport plays a crucial role in the occurrence of bovine respiratory disease $(232,233)$ and affects feed efficiency $(234)$ in newly received feedlot cattle. Ingesting antioxidants, such as vitamin $\mathrm{E}$ and related Se, can help reverse these adverse effects. When these are limited in the diet of confined ruminants consuming a limited diversity of fresh forages, supplementation can mitigate the adverse effects of stress on growth and product quality $(226,235,236)$.

\section{The Ruminal Microorganisms' Perspective}

Ruminal microbes can synthesize as well as degrade vitamins and other antioxidative dietary compounds. Diet affects this dynamic. High energy concentrate diets, for example, result in an $80 \%$ vitamin A loss in the rumen compared to only $20 \%$ breakdown in high-forage diets (237). As a result, slow-release rumen boli containing vitamins and minerals have proven effective for enhancing confined ewe reproductive functions (238). However, it is unclear if vitamins played any role and their effectiveness declines after the initial weeks. The effectiveness of slow-release $\mathrm{Cu}, \mathrm{Se}$, or Co has proven especially useful in pastures where soils and consequently forages are low in any one of these minerals. 
However, because forages typically supply vitamins above rumen microorganism requirements, their supplementation has not been widely studied in grazing or browsing ruminants. In a feedlot where fresh forages are rarely an ingredient, however, this picture changes drastically.

\section{The Consumers' Perspective}

Volatile compounds ingested by grazing and browsing lactating ruminants change milk and dairy product fatty acid profile and antioxidant properties (239-241). Not only can this extend product shelf life, but it can also be important for health benefits to consumers as well as unique flavors in milk, butter, and cheese that arise from consuming certain forages that vary by region and season (214). These are driven by forage composition, particularly dicotyledonous plant species (242). When animals are fed in confinement, supplementation can compensate for vitamin deficiencies in the animal, which is then reflected in the product (235). In North American milk production, where strong flavors are not a consumer preference, forages containing these compounds may not always be desirable.

\section{Sources of Vitamins}

The role of Vitamin $\mathrm{E}$ and other antioxidants in ruminant nutrition and health has been well-documented. Without them, animal health suffers, and production yield and quality decline. What is not always recognized is that their supplementation is largely irrelevant to pasture or rangeland-fed animals that ingest these naturally from fresh, green forages. These antioxidants readily appear in products originating from these free-ranging ruminants (214). Grazing and browsing ruminants, especially in ecosystems with diverse plant species, rarely benefit from dietary supplements. The same is not the case for confined feeding operations or monoculture grazing systems.

Confined animal feeding operations for feeding ruminants high energy diets invariably enhance animal production and health when they include synthetic vitamins and other antioxidant-enhancing supplements in the feed. This will come from fresh green forages or, in their absence, as synthetic supplements. These are generally injected to increase efficiency and bypass rumen degradation, but slow-release ruminal boli may also play a role in systems that do not lend themselves to repeated injections (238).

Very little is known about the antioxidant efficacy of feeding conserved (e.g., hays and silages) vs. freshly harvested (greenchop) forages to confined ruminants. Feeding trials comparing cut-and-carry or greenchop systems to conserved forages should also examine the role of forage species, functional groups (e.g., legumes), plant maturity, environment (e.g., soil nutrients or moisture), browse vs. grazing (especially for goats), and species diversity. Additional trials should examine the benefits of allowing animals to graze, browse, or even pen-feed selectivity (self-medication) for forages that lend themselves to greater antioxidant activity in the ruminant, animal products, and humans who consume products containing high or low concentrations of ruminant-originating antioxidants. Additional research should compare the efficacy of plant vs. synthetic vitamin sources in ruminant diets.
Should vitamins be systematically quantified in ruminant feedlot diet components? Quantifying vitamins important in ruminant cellular antioxidant functions in confined animal feed may not be as useful as measuring key minerals, mostly because the former is broken down by rumen microorganisms fed high concentrate and high energy feeds, making these unavailable for absorption in the remainder of the gastrointestinal tract. Supplementing vitamins up to minimum recommended levels has already been proven beneficial to ruminants in confinement, under heavy reproduction pressure, or under managementinduced stresses, such as handling or transport.

\section{Future Perspectives}

Additional research topics needing attention include the effectiveness of slow-release rumen boli for vitamins in feedlot systems. Timing (reproduction, weaning, season, maturity), rumen microorganism breakdown leading to inefficiencies, and duration of release all merit attention. The efficacy of slowrelease supplements for confined feeding vis-à-vis fresh forages (classes, species, maturity, diversity) also merits focus, especially regarding animal and human consumer health benefits.

The key question is, should we invest resources in this phytochemical? For pasture-based systems that include diverse forage species, including legumes and other forbs, any investment is unlikely to produce any measurable benefit except in cases where soils are deficient in key minerals, such as Se, important for antioxidant health. More research is needed in the case of confined feeding operations, especially long-duration systems, such as confined dairies. Examples include comparing the economic and health returns of year-round fresh, diverse forage systems where mild climates allow cultivation during any season.

\section{ALKALOIDS}

\section{Classification and Definitions}

Alkaloids represent the largest class of secondary plant compounds in North-American perennial plants and occur in many rangeland grasses and weeds (243), where they mostly have gained attention as a potential toxin for ruminants and other pasture livestock in case of overfeeding of alkaloidcontaining plants. Alkaloids were initially classified as cyclic compounds containing $\mathrm{N}$ in a negative oxidation state, derived from an amino acid. However, some pseudo-alkaloids are not derived from amino acids and alkaloid-like compounds (amines) that do not contain $\mathrm{N}$ within any ring-structure. Given the confusing nomenclature of alkaloids, pseudo-alkaloids, and amines, it seems more convenient to classify them based on their biogenetic origins, where four groups were created: (1) alkaloids derived from ornithine, arginine, lysine, histidine, phenylalanine, tyrosine, tryptophan, anthranilic acid, and nicotinic acid; (2) purine alkaloids (e.g., xanthine caffeine); (3) aminated terpenes (e.g., diterpene aconitine, triterpene solanine); and (4) polyketide alkaloids (e.g., coniine, coccinellines) (39). Alkaloids may be produced by plants and fungi infesting certain pastureland plants, such as the endophytic fungus $N$. coenophialum in tall fescue that contains the alkaloids peramine, ergot, and loline (244). 


\section{Nutritional Importance}

Overall, forage plants that include significant concentrations of alkaloids are considered toxic as many adverse effects in livestock exist, including acute and chronic symptoms, such as damage to the central nervous system, liver damage, muscle cramps, and death (245). The toxicological effects associated with alkaloids, specifically the broadly present class of pyrrolizidines, has been in discussion since the 1960s, specifically in context with animal production (246). Specifically, breeding efforts to remove tannins from forage for ruminants to optimize meat production may have possibly reduced tannins and alkaloids' interactions, thus increasing the toxicity of the latter (247). Many plants with high alkaloids in the leaf are not palatable to herbivores due to bitterness (248). It has been observed that wild animals (e.g., deer, rabbits) tend to limit the consumption of alkaloid containing plants but also to be highly tolerant. This resistance to chronic alkaloid intoxication has been, in part, ascribed to intestinal microbiome containing strains that can degrade alkaloids (249).

Initial efforts to remove alkaloids from the food chain of livestock production did not consider the crucial role of alkaloids across several ecological networks (245). Ergot alkaloids (e.g., ergovaline, ergonovine, ergine) are commonly found in tall fescue (Festuca arundinacea-now Schedonorus arundinaceus Schreb.; https://plants.sc.egov.usda.gov), but an endophytic fungus-Neotyphodium coenophialum-produces them. Through a mutualistic symbiotic relationship, it enables the tall fescue to thrive during drought and cold weather and resist insect predation, nematode infestation, and some diseases (244), but it can be devastating to the ruminant animal $(250,251)$. In a previous study, a genetically modified non-producing-ergot $N$. coenophialum has been incorporated into tall fescue to still yield the plant's agronomic benefits without causing toxicity to the grazing animal (244). Similarly, perennial ryegrass (Lolium perenne L.), another widely used cool-season pasture grass, is infected with $N$. lolli-an endophyte fungus that produces the biologically active ergot, peramine, and lolitrem alkaloids, which cause ryegrass staggers in livestock (244). In contrast, reed canarygrass (Phalaris arundinacea L.) produces the alkaloid gramine in leaf sheaths and stems, reducing ruminant's forage intake, thus limiting growth and development (244).

Simultaneously, various therapeutic activities have been ascribed to alkaloids, including antioxidant, cancer-preventive, antidiabetic, anti-inflammatory, and vasodilatory activities (252254), but it has not been well-investigated how livestock could benefit from these beneficial activities from alkaloids. Many plant extracts that have been investigated for the beneficial actions of contained polyphenols and terpenoids may also contain alkaloids contributing to their biological activities, for example, giant milkweed (255) or herbal mixtures containing polyphenols, terpenoids, and alkaloids (256).

Additionally, the microbiome of ruminants, including bacteria, archaea, protozoa, and fungi, in part, metabolizes alkaloids to non-toxic metabolites (257); however, causal relationships have not been well-investigated. For example, Koester et al. (258) showed that cows with high vs. low tolerance to fescue toxicosis have vastly different microbiota compositions, specifically fungal phylotypes Neocallimastigaceae, potent fiber-degrading fungi, were consistently more abundant in the tolerant cattle. Additionally, it has not been well-investigated, which microbial enzymes are required to perform alkaloid metabolism (259).

\section{Future Perspectives}

Overall, alkaloids' beneficial role to ruminants and their synergistic contributions to ecological networks in forage-animal management has not been well-investigated. The contribution of alkaloids in complex plant extracts beneficial to ruminant nutrition also remains to be explored.

\section{ESSENTIAL OILS}

\section{Classification and Definitions}

Unlike the previous phytochemicals that maintain a reasonably specific chemical makeup, EO are mixtures of compounds comprised of previously discussed phytochemicals and other intrinsic chemicals. Indeed, the nomenclature "essential oils" is a misnomer because $\mathrm{EO}$ is neither essential in the sense that animals have a daily requirement nor are oils because they contain glycerol (2). The term EO was likely derived from quinta essentia (i.e., quintessence) attributed to Bombastus Paracelsus von Hohenheim ${ }^{1493-1543}$, who used the term for any extraction of pharmacological drugs via steam distillation (260). Essential oils are classically defined as complex, multi-component mixtures of various volatile and non-volatile compounds, including acids, acetones, alcohols, aldehydes, esters, phenolics, and terpenes (261). The primary constituents of EO are low molecular weight terpenes/terpenoids and aromatic compounds, with monoterpenes representing $90 \%$ of EO (262). Essential oils are commonly extracted from materials found throughout the plant, including bark, leaves, flowers, roots, seeds, and stems. The biological properties of an EO are determined by its chemical profile that can vary depending upon the extraction process, plant material, plant maturity, and growing environment (262). In many cases, much of the pharmaceutical properties exhibited by EO can be attributed to the phytochemicals that comprise an EO (e.g., terpenes, terpenoids, phenolics, polyphenolics) (261).

Essential oils can exhibit antimicrobial, antiseptic, antiparasitic, antioxidant, anti-inflammatory, and immunomodulating activities. In general, EO display hydrophobic or lipophilic attributes that result in a high affinity for bacterial cell membranes, generating ion leakage that can ultimately result in ATP depletion and cell lysis $(263,264)$. Since ancient times, EO have been exploited by humans for their pharmaceutical properties (263), with EO currently being used regularly in agriculture, cosmetic, food, homeopathic, pharmaceutical, and therapeutic industries (262). Essential oils are cited as improving animal health and nutritional status by stimulating the circulatory, digestive, and immune systems, as well as reducing pathogenic bacteria and parasites $(261,265)$.

\section{Nutritional Importance}

The nutritional effects of EO are primarily attributed to their antimicrobial properties that are comprised of multiple interaction mechanisms. Gram-positive bacteria are considered 
more susceptible to EO than gram-negative bacteria due to both hydrophobic and lipophilic interactions affecting cell membrane stability (266). However, small molecular weight components, via hydrophobic interactions, may be able to penetrate and affect gram-negative bacteria (267). The application of EO in ruminant nutrition has focused on ruminal modulation to shift the microbial consortium toward one that improves nutrient use efficiency (268). Significant emphases have primarily remained focused on $\mathrm{N}$-metabolism, $\mathrm{CH}_{4}$ abatement, and the VFA profile $(36,264)$. Essential oils complex and varied composition may provide the potential to alleviate tolerance and resistance developments associated with medically important antimicrobials and synthetic compounds.

\section{Ruminal Fermentation}

The basis for employing EO in ruminant diets is to modify the microbial population so that efficient fermentation pathways are used, and the animal's nutrient use efficiency is increased. The primary means of accomplishing this is by altering the VFA profile (lower acetate-to-propionate ratio) and a reduction in fermentative waste products (e.g., $\mathrm{CH}_{4}$ and $\mathrm{NH}_{3}$ ). The mode of actions provided by EO suggests they may be able to modify ruminal fermentation similar to ionophores by decreasing the prevalence of Gram-positive bacteria, including hyper-ammonia producing bacteria and those that readily produce formate or $\mathrm{H}_{2}$ (269).

In vivo research has demonstrated that $\mathrm{EO}$ reduce the acetateto-propionate ratio to a level comparable to ionophores when ruminants are fed high-quality diets (e.g., dairy and feedlot) (270-274). However, this result is inconsistent, and it is not easy to discern if the decreased acetate-to-propionate ratio results from reduced acetate, increased propionate, or both, as all scenarios have been observed. An increase in butyrate has also been indicated in some studies $(270,275)$ and is cited as an indication that $\mathrm{EO}$ and ionophores have differing modes of action $(264,270)$. As well, ruminal branched-chain volatile fatty acids have been reduced $(270)$ and increased $(276,277)$ in vivo, indicating an alteration in the cellulolytic microbes or those that synthesize branched-chain volatile fatty acids from branchedchain amino acids. Both branched-chain volatile fatty acids and branched-chain amino acids are essential for the normal fermentative functions of cellulolytic microbes in the rumen (1). Overall, the addition of EO often imparts no change to the total VFA concentration $(277,278)$. However, increased $(271,279)$ and reduced $(280,281)$ total VFA concentrations have been reported, but the reduction in total VFA concentration is typically not to the extent observed with ionophores $(2,22,282)$.

The effect of EO on digestibility is a significant point of contingency, but it has not been a focal point for much of the in vivo work in beef cattle. Of those that have examined digestibility, there was no effect on DM digestibility or neutral detergent fiber digestibility $(271,272,283)$. The result is similar in dairy cattle, with only marginal effects on digestibility $(274,281,284,285)$. As with digestibility, EO's inclusion does not appear to affect significantly intake, at least not at the supplementation levels commonly used in vivo.
The provision of $\mathrm{EO}$ in vivo has not demonstrated a repeatable effect on ruminal $\mathrm{CH}_{4}$ without suppressing digestibility. Supplementing diets with $\mathrm{EO}$ has decreased $\mathrm{CH}_{4}$ in dairy cattle (286-289), but did not change of increased $\mathrm{CH}_{4}$ production in beef cattle $(277,278)$. Although $\mathrm{CH}_{4}$ production has not been measured, when feeding EO, protozoa and methanogen numbers decline in vivo with a corresponding reduction in the acetateto-propionate ratio $(270,272)$. A reduction in $\mathrm{CH}_{4}$ without inhibiting digestion has typically been observed when $\mathrm{EO}$ are provided at $\sim 500 \mathrm{mg} / \mathrm{kg} \mathrm{DM}$, but as little as $41 \mathrm{mg} / \mathrm{kg} \mathrm{DM}$ has imparted an effect. The beneficial effects are thought to be due to selective inhibition of protozoa and methanogens; however, the negative or ineffectual results are likely the result of EO demonstrating indiscriminate binding or lack of adequate biological activity.

Much research has investigated the potential application of $\mathrm{EO}$ to reduce proteolysis and deamination in the rumen. However, the consensus indicates that EO have little-to-no effect on the ruminal breakdown of protein and amino acids in beef or dairy cattle. The vast majority of research indicates no difference in ruminal $\mathrm{NH}_{3}$ when $\mathrm{EO}$ are included in the diet $(275,278-280)$. Similarly, numerous studies have failed to indicate a difference in blood or milk urea $\mathrm{N}$ from animals provided $\mathrm{EO}(274,290,291)$. The lack of effect is thought to result from EO being supplemented at too low of a rate to alter $\mathrm{N}$ metabolism (264). However, reduced ruminal digestibility had no effect on ruminal $\mathrm{NH}_{3}$ or blood urea nitrogen levels in beef heifers supplemented with EO $(292,293)$. This could indicate that some species of hyper-ammonia-producing bacteria are less sensitive to EO (294).

\section{Post-rumen Digestion}

Essential oils increase the flow of non-microbial $\mathrm{N}$ to the small intestine, as well as stimulate digestive enzymes and alter microbial populations in the lower tract. However, minimal investigation of rumen outflow and post-rumen digestion has been performed, particularly in vivo. In beef heifers, a linear increase in the flow of non-microbial $\mathrm{N}$ to the duodenum has been observed with an increasing rate of eugenol or cinnamaldehyde $(292,293)$. However, post-ruminal N digestibility does not improve when feeding EO (292, 293, 295, 296). The inclusion of EO yields equal or lesser ruminal $\mathrm{N}$ digestibility with no difference in intestinal digestibility. This results in total-tract $\mathrm{N}$ digestibility not different or lower than the control. A similar trend is present for starch and neutral detergent fiber digestibility, ruminally and postruminally. However, increased total-tract acid detergent fiber digestibility has been observed and attributed to a stimulatory effect of EO on digestive enzymes $(283,291,297)$. In ruminants, no research has directly investigated $\mathrm{EO}$ as a stimulus for gastric or intestinal enzymes. However, this is not implausible as EO have demonstrated the ability to reduce pathogenic fecal bacteria (298) and diarrhea in calves (299), as well as reduce fecal DM and viscosity in dairy cattle (274). 


\section{Methodological Aspects}

Essential oils have primarily been investigated using in vitro methods, batch or continuous culture, particularly when screening multiple compounds and rates. In many instances, batch incubations have not adequately represented the dynamic rumen environment, whereas continuous culture has provided fermentation and outflow data comparable to in vivo results. Over the past decade, in vivo methods have been regularly implemented, but efforts have mainly focused on dairy and feedlot sectors, with little to no investigation into grazing beef cattle. Much of the in vivo research focused on fermentation parameters and digestive functions has utilized low animal numbers (4-16) in Latin square or switchback designs. Some larger pen-fed studies have emphasized performance and carcass characteristics with digestive attributes being investigated with a small number of cannulated animals. A shortcoming of multiple fermentation studies is that the use of low animal numbers has not greatly progressed our knowledge of the inter-animal variation associated with $\mathrm{EO}$ provision. For in vivo investigations, the length of EO or treatment provision varies greatly. Research focusing on digestion and fermentation commonly utilized 14to 31-day feeding periods, whereas the larger performance trials typically ranged from 80 to 205 days on feed. There is an apparent deficiency in fermentation and microbiota data for animals fed EO for more than 30 days, limiting our knowledge of digestive or microbial alterations with prolonged feeding.

\section{Research Data}

The successful application of EO depends on numerous factors, but the overall effect of EO is unclear due to a lack of consistency among measured variables. Even so, EO have regularly increased intake and improved the VFA profile and feed conversion in feeder cattle, as well as reduced $\mathrm{CH}_{4}$ and increased milk yield and feed conversion in dairy cattle. The reason for the different effects between a feeder and dairy cattle is likely, at least in part, a result of differences in diet composition, particularly the level and type of roughage. However, there is little information to assist in making comparisons to high-roughage diets. In a metaanalysis of the essential oil blend, Agolin Ruminant ${ }^{\circledR}$, in dairy cattle, Belanche et al. (300) determined that supplementation of the EO blend increased milk yield and reduced $\mathrm{CH}_{4}$, and an adaptation period of at least 4 weeks was required for consistent results. Unfortunately, most digestive studies have utilized periods spanning 3-4 weeks, perhaps not allowing enough time for consistent outcomes to be realized. In a metaanalysis investigating the effects of EO in sheep diets, it was determined that $\mathrm{EO}$ increased neutral detergent fiber digestibility and propionate concentration and reduced protozoa populations and acetate concentrations (301). However, in contrast to dairy cattle, EO efficacy in sheep appeared to be highest within the first 30 days and then began diminishing. Regardless of species, the methodologies commonly used to study fermentation have not progressed our knowledge of EO efficacy with prolonged feeding.

\section{Future Perspectives}

There appears to be potential for EO to improve animal efficiency and performance, but the variation among studies makes it difficult to parse out the effect of EO vs. random variation. If $\mathrm{EO}$ are to be commercially used in ruminant production, emphasis should be placed on using methods that improve the consistency of results (i.e., increased replication, extended feeding periods, recovery methods, chromatographic methods to determine purity). Research using forage diets merit increased attention, as improved fermentation profiles would greatly benefit this sector. Apart from nutrition, there seem to be EO opportunities for internal and external parasite control. Multiple in vitro studies have reported acaricidal activity of EO and have successfully used them to control cattle ticks (302-304), with evidence indicating EO as a potential method of controlling flies and lice (305-307). This is a vital area of research due to the rapid increase in parasite resistance to synthetic compounds, providing a large opportunity to investigate feed-through and topically administered EO in ruminant species. Another area that merits attention is the effect of EO on thermal stress. There is scientific and anecdotal evidence indicating that EO's provision may reduce the stress associated with hyperthermia (308-310), but the underlying mechanisms and efficacy in a production scenario are unknown. Although EO's nutritional effects may not be consistent, there is potential for EO to improve other health parameters that directly and indirectly affect the nutritional status of ruminants.

Should researchers invest resources in EO? Based on the current literature, adequate data point to the benefits of EO to ruminant production. Additional efforts should invest in the long-term and diversity of these compounds. However, research projects must be performed in a manner that better capture the effect of EO and promotes consistency among trials, rather than focusing on the least publishable unit.

\section{CONCLUSION}

Many scientists embarked on alternative replacements to antibiotics in animal operations in the last 15 years after widespread concern over AMR due to antibiotics' perceived broad use in animal production. Phytochemicals became the preferred research pursuit, even though these compounds have been studied and applied in many fields long before AMR became publicized. Phytochemicals embody a broad spectrum of chemical components produced by plants and some fungi to act as chemicals against predatorial microbes, insects, and herbivores. Therefore, the idea of using them to manipulate ruminal fermentation and to establish other phytochemoprophylactic (prevent animal diseases) and phytochemotherapeutic (treat animal diseases) activities gained sympathizers.

Flavonoids comprise only $9 \%$ of known phytochemical compounds, but most research has been dedicated to this group, especially CT. However, because of inconclusive or contradictory findings, more targeted research is needed to confirm and validate published findings before definitive recommendations of phytochemicals usage in ruminant nutrition are drawn, such as what, when, and how much to use. Although some discoveries are 
encouraging, disagreements and lack of repeatability exist among studies, particularly for CT and saponins.

Alkaloids may also have a potential untapped benefit in ruminant nutrition. Although humans have long used alkaloids for their pharmacological properties, their phytochemical usage as feed additives in ruminants has not been sufficiently scrutinized. In part, given the intricacies in measuring and classifying alkaloids chemically, they may act as ghost compounds alongside other phytochemicals of known importance as plants produce many phytochemicals concurrently.

Likewise, terpenes, vitamins, essential oils, and other natural plant antioxidants play a large role in rumen ecology and function. These are most prevalent but least studied in fresh forages, especially in rangelands. The difficulty of isolating their individual effects in forage-based systems make them especially challenging to describe. This, however, does not detract from the critical roles they plan in ruminant ecosystems. The importance and individual effects are more easily identified in feedlot situations where concentrates and preserved forages contain

\section{REFERENCES}

1. Tedeschi LO, Fox DG. The Ruminant Nutrition System: Volume I - An Applied Model for Predicting Nutrient Requirements and Feed Utilization in Ruminants. Ann Arbor, MI: XanEdu (2020).

2. Tedeschi LO, Nagaraja TG. Rumen modifiers. In: Tedeschi LO, Nagaraja TG, editors. Rumen Health Compendium. Ann Arbor, MI: XanEdu (2020). p. $35-46$.

3. Crozier A, Jaganath IB, Clifford MN. Phenols, polyphenols and tannins: an overview. In: Crozier A, Clifford MN, Ashihara H, editors. Plant Secondary Metabolites. Oxford: Blackwell Publishing Ltd. (2006). p. 1-24.

4. Tohge T, Watanabe M, Hoefgen R, Fernie AR. The evolution of phenylpropanoid metabolism in the green lineage. Crit Rev Biochem Mol Biol. (2013) 48:123-52. doi: 10.3109/10409238.2012.758083

5. Hahlbrock K. Flavonoids. In: Stumpf PK, Conn EE, editors. The Biochemistry of Plants; A Comprehensive Treatise; Secondary Plant Products. San Diego, CA: Academic Press (1981). p. 425-56.

6. Kutchan TM, Gershenzon J, Møller BL, Gang DR. Natural products (secondary metabolites). In: Buchanan BB, Gruissem W, Jones RL, editors. Biochemistry \& Molecular Biology of Plants. 2nd ed. Chichester: Wiley Blackwell (2015). p. 1132-206.

7. Harborne JB. Phytochemical Methods: A Guide to Modern Techniques of Plant Analysis. New York, NY; Dordrecht: Springer (1984).

8. Ramírez-Restrepo CA, Barry TN. Alternative temperate forages containing secondary compounds for improving sustainable productivity in grazing ruminants. Anim Feed Sci Technol. (2005) 120:179-201. doi: 10.1016/j.anifeedsci.2005.01.015

9. Ramírez-Restrepo CA, Barry TN, Marriner A, López-Villalobos N, McWilliam EL, Lassey KR, et al. Effects of grazing willow fodder blocks upon methane production and blood composition in young sheep. Anim Feed Sci Technol. (2010) 155:33-43. doi: 10.1016/j.anifeedsci.2009.10.003

10. Waghorn GC, Ulyatt MJ, John A, Fisher MT. The effect of condensed tannins on the site of digestion of amino acids and other nutrients in sheep fed on Lotus corniculatus L. Br J Nutr. (1987) 57:115-26. doi: 10.1079/BJN19870015

11. Mangan JL. Nutritional effects of tannins in animal feeds. Nutr Res Rev. (1988) 1:209-31. doi: 10.1079/NRR19880015

12. Ramírez-Restrepo CA, Barry TN, López-Villalobos N, Kemp PD, Harvey TG. Use of Lotus corniculatus containing condensed tannins to increase reproductive efficiency in ewes under commercial dryland farming conditions. Anim Feed Sci Technol. (2005) 121:23-43. doi: 10.1016/j.anifeedsci.2005.02.006 fewer compounds, with consequent adverse effects on rumen microbiome health and ruminant nutrition. More research in these compounds in concentrated animal feeding operations is therefore merited.

The phytochemicals' role in sustainable ruminant production is undeniable, but much uncertainty remains. Scientists have yet to answer the sustainability issues before relying exclusively on phytochemicals as a sensational remedy for AMR, especially in complete rations lacking fresh forages and precluding ruminant feed selection. Phytochemical feed additives may have a place in sustainable production scenarios only if more convincing results of their efficacy and effectiveness in replacing antibiotics are dependably identified. The old saying "do not put all your eggs in one basket" still applies to phytochemical research.

\section{AUTHOR CONTRIBUTIONS}

All authors listed have made a substantial, direct and intellectual contribution to the work, and approved it for publication.

13. Barry TN, Parkinson TJ, Ramirez-Restrepo CA, McWilliam EL, LopezVillalobos N. Can mating ewes on condensed tannin-containing forages be used to reduce lamb mortality between birth and weaning? In: Proceedings of the New Zealand Society of Animal Production, New Zealand Society of Animal Production, Hamilton (2004).

14. Ramírez-Restrepo CA, Pernthaner A, Barry TN, López-Villalobos $\mathrm{N}$, Shaw RJ, Pomroy WE, et al. Characterization of immune responses against gastrointestinal nematodes in weaned lambs grazing willow fodder blocks. Anim Feed Sci Technol. (2010) 155:99-110. doi: 10.1016/j.anifeedsci.2009.10.006

15. Tedeschi LO, Ramírez-Restrepo CA, Muir JP. Developing a conceptual model of possible benefits of condensed tannins for ruminant production. Animal. (2014) 8:1095-105. doi: 10.1017/S175173111 4000974

16. Lillehoj H, Liu Y, Calsamiglia S, Fernandez-Miyakawa ME, Chi F, Cravens $\mathrm{RL}$, et al. Phytochemicals as antibiotic alternatives to promote growth and enhance host health. Vet Res. (2018) 49:76. doi: 10.1186/s13567-018-0562-6

17. Frutos P, Hervás G, Natalello A, Luciano G, Fondevila M, Priolo A, et al. Ability of tannins to modulate ruminal lipid metabolism and milk and meat fatty acid profiles. Anim Feed Sci Technol. (2020) 269:114623. doi: 10.1016/j.anifeedsci.2020.114623

18. Ramírez-Restrepo CA, Barry TN, López-Villalobos N, Kemp PD, McNabb WC. Use of Lotus corniculatus containing condensed tannins to increase lamb and wool production under commercial dryland farming conditions without the use of anthelmintics. Anim Feed Sci Technol. (2004) 117:85-105. doi: 10.1016/j.anifeedsci.2004.05.005

19. Ramírez-Restrepo CA, Barry TN, Pomroy WE, López-Villalobos N, McNabb WC, Kemp PD. Use of Lotus corniculatus containing condensed tannins to increase summer lamb growth under commercial dryland farming conditions with minimal anthelmintic drench input. Anim Feed Sci Technol. (2005) 122:197-217. doi: 10.1016/j.anifeedsci.2005.03.009

20. Mupeyo B, Barry TN, Pomroy WE, Ramírez-Restrepo CA, López-Villalobos N, Pernthaner A. Effects of feeding willow (Salix spp.) upon death of established parasites and parasite fecundity. Anim Feed Sci Technol. (2011) 164:8-20. doi: 10.1016/j.anifeedsci.2010.11.015

21. Kornele ML, McLean MJ, O’Brien AE, Phillippi-Taylor AM. Antiparasitic resistance and grazing livestock in the United States. J Am Vet Med Assoc. (2014) 244:1020-2. doi: 10.2460/javma.244.9.1020

22. Tedeschi LO, Callaway TR, Muir JP, Anderson R. Potential environmental benefits of feed additives and other strategies for ruminant production. Rev Brasil Zoot. (2011) 40:291-309. 
23. Chen D, Chen G, Sun Y, Zeng X, Ye H. Physiological genetics, chemical composition, health benefits and toxicology of tea (Camellia sinensis L.) flower: a review. Food Res Int. (2020) 137:109584. doi: 10.1016/j.foodres.2020.109584

24. Fan L, He Y, Xu Y, Li P, Zhang J, Zhao J. Triterpenoid saponins in tea (Camellia sinensis) plants: biosynthetic gene expression, content variations, chemical identification and cytotoxicity. Int J Food Sci Nutr. (2020):1-16. doi: 10.1080/09637486.2020.1798891

25. Jiang X, Cao Y, Jørgensen LG, Strobel BW, Hansen HCB, Cedergreen N. Where does the toxicity come from in saponin extract? Chemosphere. (2018) 204:243-50. doi: 10.1016/j.chemosphere.2018.04.044

26. Younes M, Aquilina G, Castle L, Engel KH, Fowler P, Frutos Fernandez MJ, et al. Re-evaluation of quillaia extract (E 999) as a food additive and safety of the proposed extension of use. Eur Food Saf Authority J. (2019) 17:e05622. doi: 10.2903/j.efsa.2019.5622

27. Wina E, Muetzel S, Hoffmann E, Makkar HPS, Becker K. Saponins containing methanol extract of Sapindus rarak affect microbial fermentation, microbial activity and microbial community structure in vitro. Anim Feed Sci Technol. (2005) 121:159-74. doi: 10.1016/j.anifeedsci.2005.02.016

28. Fajriaty I, Hariyanto I, Haryanto Y. Anti-fertility effect of ethanol extract of lerak (Sapindus rarak DC) fruits in female Sprague Dawley Rats. Nusantara Biosci. (2017) 9:102-6. doi: 10.13057/NUSBIOSCI/N090118

29. Moreira AL, Scariot DB, Pelegrini BL, Pessini GL, Ueda-Nakamura T, Nakamura CV, et al. Acyclic sesquiterpenes from the fruit pericarp of Sapindus saponaria induce ultrastructural alterations and cell death in Leishmania amazonensis. Evid Based Complement Altern Med. (2017) 2017:5620693. doi: 10.1155/2017/5620693

30. Gasca CA, Dassoler M, Dotto Brand G, de Medeiros Nóbrega YK, Gomes SM, Masrouah Jamal C, et al. Chemical composition and antifungal effect of ethanol extract from Sapindus saponaria $\mathrm{L}$. fruit against banana anthracnose. Sci Horticult. (2020) 259:108842. doi: 10.1016/j.scienta.2019.108842

31. Sun DS, Jin X, Shi B, Xu Y, Yan S. Effects of Yucca schidigera on gas mitigation in livestock production: a review. Braz Archiv Biol Technol. (2017) 60. doi: 10.1590/1678-4324-2017160359

32. Qu L, Wang J, Ruan J, Yao X, Huang P, Wang Y, et al. Spirostanetype saponins obtained from Yucca schidigera. Molecules. (2018) 23:167. doi: 10.3390/molecules23010167

33. Greathead H. Plants and plant extracts for improving animal productivity. Proc Nutr Soc. (2003) 62:279-90. doi: 10.1079/PNS20 02197

34. Valenzuela-Grijalva NV, Pinelli-Saavedra A, Muhlia-Almazan A, Domínguez-Díaz D, González-Ríos H. Dietary inclusion effects of phytochemicals as growth promoters in animal production. J Anim Sci Technol. (2017) 59:1-17. doi: 10.1186/s40781-017-0133-9

35. Hassan YI, Lahaye L, Gong MM, Peng J, Gong J, Liu S, et al. Innovative drugs, chemicals, and enzymes within the animal production chain. Vet Res. (2018) 49:71. doi: 10.1186/s13567-018-0559-1

36. Calsamiglia S, Busquet M, Cardozo PW, Castillejos L, Ferret A. Invited review: essential oils as modifiers of rumen microbial fermentation. J Dairy Sci. (2007) 90:2580-95. doi: 10.3168/jds.2006-644

37. Lovett JV, Hoult AHC. Allelopathy in plants. In: Roberts MF, Winks M, editors. Alkaloids: Biochemistry, Ecology, and Medicinal Applications. New York, NY: Plenum Press (1998). p. 337-47.

38. Harborne JB. Introduction to Ecological Biochemistry. New York, NY: Elsevier; Academic Press (1993).

39. Roberts MF, Winks M. Alkaloids: Biochemistry, Ecology, and Medicinal Applications. New York, NY: Plenum Press (1998).

40. Waller GR, Dermer OC. Enzymology of alkaloid metabolism in plants and microorganisms. In: Stumpf PK, Conn EE, editors. The Biochemistry of Plants; A Comprehensive Treatise; Secondary Plant Products. San Diego, CA: Academic Press (1981). p. 317-402.

41. Southon IW, Buckingham J. Dictionary of Alkaloids. New York, NY: Chapman and Hall Ltd. (1989).

42. Schmeller T, Wink M. Utilization of alkaloids in modern medicine. In: Roberts MF, Winks M, editors. Alkaloids: Biochemistry, Ecology, and Medicinal Applications. New York, NY: Plenum Press (1998). p. 435-59.

43. Naumann HD, Tedeschi LO, Zeller WE, Huntley NF. The role of condensed tannins in ruminant animal production: advances, limitations, and future directions. Rev Brasil Zoot. (2017) 46:929-49. doi: 10.1590/s1806-92902017001200009

44. Patra AK, Saxena J. Exploitation of dietary tannins to improve rumen metabolism and ruminant nutrition. J Sci Food Agric. (2011) 91:24-37. doi: $10.1002 /$ jsfa.4152

45. Van Buren JP, Robinson WB. Formation of complexes between protein and tannic acid. J Agric Food Chem. (1969) 17:772-7. doi: 10.1021/jf60164a003

46. Asquith TN, Butler LG. Interactions of condensed tannins with selected proteins. Phytochemistry. (1986) 25:1591-3. doi: 10.1016/S0031-9422(00)81214-5

47. Simon SA, Disalvo EA, Gawrisch K, Borovyagin V, Toone E, Schiffman SS, et al. Increased adhesion between neutral lipid bilayers: interbilayer bridges formed by tannic acid. Biophys J. (1994) 66:1943-58. doi: 10.1016/S0006-3495(94)80988-9

48. Lou W, Bezusov A, Li B, Dubova? Recent advances in studying tannic acid and its interaction with proteins and polysaccharides. Food Sci Technol. (2019) 13:63-9. doi: 10.15673/fst.v13i3.1452

49. Zeng X, Du Z, Xu Y, Sheng Z, Jiang W. Characterization of the interactions between apple condensed tannins and biologically important metal ions $\left[\mathrm{Fe}^{2+}\left(3 \mathrm{~d}^{6}\right), \mathrm{Cu}^{2+}\left(3 \mathrm{~d}^{9}\right)\right.$ and $\left.\mathrm{Zn}^{2+}\left(3 \mathrm{~d}^{10}\right)\right]$. Lebensmittel Wissenschaft Technol. (2019) 114:108384. doi: 10.1016/j.lwt.2019.108384

50. Guimarães-Beelen PM, Berchielli TT, Beelen R, Medeiros AN. Influence of condensed tannins from Brazilian semi-arid legumes on ruminal degradability, microbial colonization and ruminal enzymatic activity in Saanen goats. Small Rumin Res. (2006) 61:35-44. doi: 10.1016/j.smallrumres.2005.01.007

51. Bao Y, Zhou K, Zhao G. Nitrous oxide emissions from the urine of beef cattle as regulated by dietary crude protein and gallic acid. J Anim Sci. (2018) 96:3699-711. doi: 10.1093/jas/sky252

52. Peng K, Jin L, Niu YD, Huang Q, McAllister TA, Yang HE, et al. Condensed tannins affect bacterial and fungal microbiomes and mycotoxin production during ensiling and upon aerobic exposure. Appl Environ Microbiol. (2018) 84:e02274-17. doi: 10.1128/AEM.02274-17

53. Butler LG. Antinutritional effects of condensed and hydrolyzable tannins. In: Hemingway RW, Laks PE, editors. Plant Polyphenols: Synthesis, Properties, Significance. Boston, MA: Springer US (1992). p. 693-8.

54. Aboagye IA, Oba M, Koenig KM, Zhao GY, Beauchemin KA. Use of gallic acid and hydrolyzable tannins to reduce methane emission and nitrogen excretion in beef cattle fed a diet containing alfalfa silage. J Anim Sci. (2019) 97:2230-44. doi: 10.1093/jas/skz101

55. Acevedo-Ramírez PMC, Hallal-Calleros C, Flores-Pérez I, Alba-Hurtado F, Mendoza-Garfías MB, Castro del Campo N, et al. Anthelmintic effect and tissue alterations induced in vitro by hydrolysable tannins on the adult stage of the gastrointestinal nematode Haemonchus contortus. Vet Parasitol. (2019) 266:1-6. doi: 10.1016/j.vetpar.2018.12.008

56. Herremans S, Decruyenaere V, Cantalapiedra-Hijar G, Beckers Y, Froidmont E. Effects of hydrolysable tannin-treated grass silage on milk yield and composition, nitrogen partitioning and nitrogen isotopic discrimination in lactating dairy cows. Animal. (2020) 14:771-9. doi: 10.1017/S175173111900226X

57. Makkar HPS, Becker K, Abel H, Szegletti C. Degradation of condensed tannins by rumen microbes exposed to quebracho tannins (QT) in rumen simulation technique (RUSITEC) and effects of QT on fermentative processes in the RUSITEC. J Sci Food Agric. (1995) 69:495-500. doi: 10.1002/jsfa.2740690414

58. Robbins CT, Hagerman AE, Austin PJ, McArthur C, Hanley TA. Variation in mammalian physiological responses to a condensed tannin and its ecological implications. J Mammal. (1991) 72:480-6. doi: 10.2307/1382130

59. Kronberg SL, Zeller WE, Waghorn GC, Grabber JH, Terrill TH, Liebig MA. Effects of feeding Lespedeza cuneata pellets with Medicago sativa hay to sheep: nutritional impact, characterization and degradation of condensed tannin during digestion. Anim Feed Sci Technol. (2018) 245:41-7. doi: 10.1016/j.anifeedsci.2018.08.011

60. Desrues O, Mueller-Harvey I, Pellikaan WF, Enemark HL, Thamsborg SM. Condensed tannins in the gastrointestinal tract of cattle after sainfoin (Onobrychis viciifolia) intake and their possible relationship with anthelmintic effects. J Agric Food Chem. (2017) 65:1420-7. doi: 10.1021/acs.jafc.6b05830 
61. Fagundes GM, Benetel G, Welter KC, Melo FA, Muir JP, Carriero MM, et al. Tannin as a natural rumen modifier to control methanogenesis in beef cattle in tropical systems: friend or foe to biogas energy production? Res Vet Sci. (2020) 132:88-96. doi: 10.1016/j.rvsc.2020.05.010

62. Norris AB, Crossland WL, Tedeschi LO, Foster JL, Muir JP, Pinchak WE, et al. Inclusion of quebracho tannin extract in a high-roughage cattle diet alters digestibility, nitrogen balance, and energy partitioning. J Anim Sci. (2020) 98:1-12. doi: 10.1093/jas/skaa047

63. Grazziotin RCB, Halfen J, Rosa F, Schmitt E, Anderson JL, Ballard V, et al. Altered rumen fermentation patterns in lactating dairy cows supplemented with phytochemicals improve milk production and efficiency. J Dairy Sci. (2020) 103:301-12. doi: 10.3168/jds.2019-16996

64. Becker PM, van Wikselaar PG, Franssen MCR, de Vos RCH, Hall RD, Beekwilder J. Evidence for a hydrogen-sink mechanism of $(+)$ catechinmediated emission reduction of the ruminant greenhouse gas methane. Metabolomics. (2014) 10:179-89. doi: 10.1007/s11306-013-0554-5

65. Vasta V, Daghio M, Cappucci A, Buccioni A, Serra A, Viti C, et al. Invited review: plant polyphenols and rumen microbiota responsible for fatty acid biohydrogenation, fiber digestion, and methane emission: experimental evidence and methodological approaches. J Dairy Sci. (2019) 102:3781-804. doi: 10.3168/jds.2018-14985

66. Goel G, Makkar HPS. Methane mitigation from ruminants using tannins and saponins. Trop Anim Health Prod. (2012) 44:729-39. doi: 10.1007/s11250-011-9966-2

67. Piñeiro-Vázquez AT, Canul-Solis JR, Alayón-Gamboa JA, Chay-Canul AJ, Ayala-Burgos AJ, Solorio-Sánchez FJ, et al. Energy utilization, nitrogen balance and microbial protein supply in cattle fed Pennisetum purpureum and condensed tannins. J Anim Physiol Anim Nutr. (2017) 101:159-69. doi: 10.1111/jpn.12436

68. Ebert PJ, Bailey EA, Shreck AL, Jennings JS, Cole NA. Effect of condensed tannin extract supplementation on growth performance, nitrogen balance, gas emissions, and energetic losses of beef steers. J Anim Sci. (2017) 95:134555. doi: 10.2527/jas.2016.0341

69. Yang K, Wei C, Zhao GY, Xu ZW, Lin SX. Effects of dietary supplementing tannic acid in the ration of beef cattle on rumen fermentation, methane emission, microbial flora and nutrient digestibility. J Anim Physiol Anim Nutr. (2017) 101:302-10. doi: 10.1111/jpn.12531

70. Aboagye IA, Oba M, Castillo AR, Koenig KM, Iwaasa AD, Beauchemin KA. Effects of hydrolyzable tannin with or without condensed tannin on methane emissions, nitrogen use, and performance of beef cattle fed a high-forage diet. J Anim Sci. (2018) 96:5276-86. doi: 10.1093/jas/sky352

71. Durmic Z, Ramírez-Restrepo CA, Gardiner C, O’Neill CJ, Hussein E, Vercoe PE. Differences in the nutrient concentrations, in vitro methanogenic potential and other fermentative traits of tropical grasses and legumes for beef production systems in northern Australia. J Sci Food Agric. (2017) 97:4075-86. doi: 10.1002/jsfa.8274

72. Vandermeulen S, Singh S, Ramírez-Restrepo CA, Kinley RD, Gardiner CP, Holtum JAM, et al. In vitro assessment of ruminal fermentation, digestibility and methane production of three species of Desmanthus for application in northern Australian grazing systems. Crop Pasture Sci. (2018) 69:797-807. doi: $10.1071 / \mathrm{CP} 17279$

73. Naumann HD, Tedeschi LO, Muir JP, Lambert BD, Kothmann MM. Effect of molecular weight of condensed tannins from warm-season perennial legumes on ruminal methane production in vitro. Biochem Syst Ecol. (2013) 50:154-62. doi: 10.1016/j.bse.2013.03.050

74. Melesse A, Steingass H, Schollenberger M, Holstein J, Rodehutscord M. Nutrient compositions and in vitro methane production profiles of leaves and whole pods of twelve tropical multipurpose tree species cultivated in Ethiopia. Agrofor Syst. (2019) 93:135-47. doi: 10.1007/s10457-017-0110-9

75. Ouda J, Nsahlai I, Mahundu P. In vitro degradability and gas production parameters of Sericea lespedeza (Lespedeza cuneata) mixed with varying types and levels of roughages. South Afr J Anim Sci. (2006) 36:111-21. doi: 10.4314/sajas.v36i2.3993

76. Naumann HD, Stewart WC, Whitney TR. The effect of maturity on concentration and biological activity of protein precipitating polyphenolics in ground juniper is dependent upon species. Anim Feed Sci Technol. (2018) 246:11-7. doi: 10.1016/j.anifeedsci.2018.09.013
77. El-Zaiat HM, Kholif AE, Moharam MS, Attia MF, Abdalla AL, Sallam SMA. The ability of tanniniferous legumes to reduce methane production and enhance feed utilization in Barki rams: in vitro and in vivo evaluation. Small Rumin Res. (2020) 193:106259. doi: 10.1016/j.smallrumres.2020.106259

78. Corea EE, Castro-Montoya J, Mendoza MV, López FM, Martinez A, Alvarado $\mathrm{ME}$, et al. Effect of forage source and dietary rumen-undegradable protein on nutrient use and growth in dairy heifers. Anim Feed Sci Technol. (2020) 269:114658. doi: 10.1016/j.anifeedsci.2020.114658

79. Kamel HEM, Al-Dobaib SN, Salem AZM. Dietary supplementation of sunflower oil and quebracho tannins in sheep feeding: in vivo nutrient digestibility, nitrogen utilization and in vitro ruminal degradation kinetics. J Sci Food Agric. (2019) 99:4211-7. doi: 10.1002/jsfa.9651

80. Lagrange S, Beauchemin KA, MacAdam J, Villalba JJ. Grazing diverse combinations of tanniferous and non-tanniferous legumes: implications for beef cattle performance and environmental impact. Sci Total Environ. (2020) 746:140788. doi: 10.1016/j.scitotenv.2020.140788

81. Norris AB, Tedeschi LO, Muir JP, Foster JL, Casey KD, Pinchak WE. Effect of quebracho condensed tannin extract on fecal gas flux in steers. J Environ Qual. (2020) 49:1225-35. doi: 10.1002/jeq2.20110

82. Dentinho MTP, Paulos K, Francisco A, Belo AT, Jerónimo E, Almeida J, et al. Effect of soybean meal treatment with Cistus ladanifer condensed tannins in growth performance, carcass and meat quality of lambs. Livestock Sci. (2020) 236:104021. doi: 10.1016/j.livsci.2020.104021

83. Norris AB, Tedeschi LO, Foster JL, Muir JP, Pinchak WE, Fonseca MA. AFST: Influence of quebracho tannin extract fed at differing rates within a high-roughage diet on the apparent digestibility of dry matter and fiber, nitrogen balance, and fecal gas flux. Anim Feed Sci Technol. (2020) 260:114365. doi: 10.1016/j.anifeedsci.2019.114365

84. Powell JM, Aguerre MJ, Wattiaux MA. Tannin extracts abate ammonia emissions from simulated dairy barn floors. J Environ Qual. (2011) 40:90714. doi: $10.2134 /$ jeq 2010.0492

85. Mahachi LN, Chikwanha OC, Katiyatiya CLF, Marufu MC, Aremu AO, Mapiye C. Sericea lespedeza (Lespedeza juncea var. sericea) for sustainable small ruminant production: feed, helminth suppressant and meat preservation capabilities. Anim Feed Sci Technol. (2020) 270:114688. doi: 10.1016/j.anifeedsci.2020.114688

86. Dykes G, Terrill T, Whitely N, Singh A, Mosjidis J, Burke J, et al. Effect of ground and pelleted Sericea lespedeza whole plant and leaf only on gastrointestinal nematode and coccidial infection in goats. J Agric Sci Technol. (2019) 9:91-102. doi: 10.17265/2161-6256/2019.02.003

87. Acharya M, Burke JM, Miller JE, Terrill TH, Wood EL, Muir JP. Quebracho tannins aid in the control of Eimeria spp. and gastrointestinal nematodes in lambs and goat kids. Vet Parasitol. (2020) 288:109295. doi: 10.1016/j.vetpar.2020.109295

88. Novobilský A, Mueller-Harvey I, Thamsborg SM. Condensed tannins act against cattle nematodes. Vet Parasitol. (2011) 182:213-20. doi: 10.1016/j.vetpar.2011.06.003

89. Moreno-Gonzalo J, Manolaraki F, Frutos P, Hervás G, Celaya R, Osoro K, et al. In vitro effect of heather (Ericaceae) extracts on different development stages of Teladorsagia circumcincta and Haemonchus contortus. Vet Parasitol. (2013) 197:235-43. doi: 10.1016/j.vetpar.2013.05.010

90. García-Hernández C, Rojo-Rubio R, Olmedo-Juárez A, Zamilpa A, Mendoza de Gives P, Antonio-Romo IA, et al. Galloyl derivatives from Caesalpinia coriaria exhibit in vitro ovicidal activity against cattle gastrointestinal parasitic nematodes. Exp Parasitol. (2019) 200:16-23. doi: 10.1016/j.exppara.2019.03.012

91. Villalba JJ, Miller J, Ungar ED, Landau SY, Glendinning J. Ruminant selfmedication against gastrointestinal nematodes: evidence, mechanism, and origins. Parasite. (2014) 21:31-31. doi: 10.1051/parasite/2014032

92. Costes-Thiré M, Villalba JJ, Hoste H, Ginane C. Increased intake and preference for tannin-rich sainfoin (Onobrychis viciifolia) pellets by both parasitized and non-parasitized lambs after a period of conditioning. Appl Anim Behav Sci. (2018) 203:11-8. doi: 10.1016/j.applanim.2018.02.015

93. Gaudin E, Costes-Thiré M, Villalba JJ, Hoste H, Gerfault V, Ginane C. Relative abilities of young sheep and goats to self-medicate with tanninrich sainfoin when infected with gastrointestinal nematodes. Animal. (2019) 13:1498-507. doi: $10.1017 /$ S175173111800304X 
94. Naumann H, Sepela R, Rezaire A, Masih SE, Zeller WE, Reinhardt LA, et al. Relationships between structures of condensed tannins from texas legumes and methane production during in vitro rumen digestion. Molecules. (2018) 23:2123. doi: 10.3390/molecules23092123

95. Lorenz MM, Alkhafadji L, Stringano E, Nilsson S, Mueller-Harvey I, Udén P. Relationship between condensed tannin structures and their ability to precipitate feed proteins in the rumen. J Sci Food Agric. (2014) 94:963-8. doi: 10.1002/jsfa.6344

96. Marsh KJ, Wallis IR, Kulheim C, Clark R, Nicolle D, Foley WJ, et al. New approaches to tannin analysis of leaves can be used to explain in vitro biological activities associated with herbivore defence. New Phytol. (2020) 225:488-98. doi: 10.1111/nph.16117

97. Zeller WE, Reinhardt LA, Robe JT, Sullivan ML, Panke-Buisse K. Comparison of protein precipitation ability of structurally diverse procyanidin-rich condensed tannins in two buffer systems. J Agric Food Chem. (2020) 68:2016-23. doi: 10.1021/acs.jafc.9b06173

98. Engström MT, Arvola J, Nenonen S, Virtanen VTJ, Leppä MM, Tähtinen P, et al. Structural features of hydrolyzable tannins determine their ability to form insoluble complexes with bovine serum albumin. J Agric Food Chem. (2019) 67:6798-808. doi: 10.1021/acs.jafc.9b02188

99. Hagerman AE, Butler LG. The specificity of proanthocyanidin-protein interactions. J Biol Chem. (1981) 256:4494-7.

100. Osborne NJT, McNeill DM. Characterisation of Leucaena condensed tannins by size and protein precipitation capacity. J Sci Food Agric. (2001) 81:1113-9. doi: $10.1002 /$ jsfa.920

101. McNabb WC, Peters JS, Foo LY, Waghorn GC, Jackson FS. Effect of condensed tannins prepared from several forages on the in vitro precipitation of ribulose-1,5-bisphosphate carboxylase (Rubisco) protein and its digestion by trypsin (EC 2.4.21.4) and chymotrypsin (EC 2.4.21.1). J Sci Food Agric. (1998) 77:201-12. doi: 10.1002/(SICI)1097-0010(199806)77:2<201::AIDJSFA26>3.0.CO;2-J

102. McArthur C, Sanson GD, Beal AM. Salivary proline-rich proteins in mammals: roles in oral homeostasis and counteracting dietary tannin. J Chem Ecol. (1995) 21:663-91. doi: 10.1007/BF020 33455

103. Ward D, Schmitt MH, Shrader AM. Are there phylogenetic differences in salivary tannin-binding proteins between browsers and grazers, and ruminants and hindgut fermenters? Ecol Evol. (2020) 10:10426-39. doi: $10.1002 /$ ece 3.6698

104. Schmitt MH, Ward D, Shrader AM. Salivary tannin-binding proteins: a foraging advantage for goats? Livestock Sci. (2020) 234:103974. doi: 10.1016/j.livsci.2020.103974

105. Cooper CE, Naumann HD, Lambert BD, Muir JP, Kattes DH. Legume protein precipitable phenolic and nutrient concentration responses to defoliation and ontogeny. J Plant Interact. (2014) 9:468-77. doi: 10.1080/17429145.2013.860561

106. Ramírez-Restrepo CA, Barry TN, López-Villalobos N. Organic matter digestibility of condensed tannin-containing Lotus corniculatus and its prediction in vitro using cellulase/hemicellulase enzymes. Anim Feed Sci Technol. (2006) 125:61-71. doi: 10.1016/j.anifeedsci.2005. 05.012

107. Vincken JP, Heng L, de Groot A, Gruppen H. Saponins, classification and occurrence in the plant kingdom. Phytochemistry. (2007) 68:275-97. doi: $10.1016 /$ j.phytochem.2006.10.008

108. Liu C, Qu Y, Guo P, Xu C, Ma Y, Luo H. Effects of dietary supplementation with alfalfa (Medicago sativa L.) saponins on lamb growth performance, nutrient digestibility, and plasma parameters. Anim Feed Sci Technol. (2018) 236:98-106. doi: 10.1016/j.anifeedsci.2017.12.006

109. Buyankhishig B, Murata T, Suganuma K, Batkhuu J, Sasaki K. Hyaluronidase inhibitory saponins and a trypanocidal isoflavonoid from the aerial parts of Oxytropis lanata. Fitoterapia. (2020) 145:104608. doi: 10.1016/j.fitote.2020.104608

110. Tava A, Biazzi E, Ronga D, Mella M, Doria F, Accogli R, et al. Triterpenic saponins from Medicago marina L. Phytochemistry. (2020) 174:112333. doi: 10.1016/j.phytochem.2020.112333

111. Han Q, Li K, Dong X, Luo Y, Zhu B. Function of Thelenota ananas saponin desulfated holothurin a in modulating cholesterol metabolism. Sci Rep. (2018) 8:9506. doi: 10.1038/s41598-018-27932-x
112. Li Y, Wang R, Xun X, Wang J, Bao L, Thimmappa R, et al. Sea cucumber genome provides insights into saponin biosynthesis and aestivation regulation. Cell Discov. (2018) 4:29-29. doi: 10.1038/s41421-018-0030-5

113. Moses T, Papadopoulou KK, Osbourn A. Metabolic and functional diversity of saponins, biosynthetic intermediates and semi-synthetic derivatives. Crit Rev Biochem Mol Biol. (2014) 49:439-62. doi: 10.3109/10409238.2014.953628

114. Kharkwal H, Bahuguna DP, Pant M, Kharkwal H, Kharkwal A, Joshi D. Foaming glycosides: a review. IOSR J Pharm. (2012) 2:23-8. doi: 10.9790/3013-25202328

115. Klita PT, Mathison GW, Fenton TW, Hardin RT. Effects of alfalfa root saponins on digestive function in sheep. J Anim Sci. (1996) 74:1144-56. doi: $10.2527 / 1996.7451144 x$

116. Marrelli M, Conforti F, Araniti F, Statti GA. Effects of saponins on lipid metabolism: a review of potential health benefits in the treatment of obesity. Molecules. (2016) 21:1404. doi: 10.3390/molecules21101404

117. Thakur M, Melzig MF, Fuchs H, Weng A. Chemistry and pharmacology of saponins: special focus on cytotoxic properties. Bot Targets Ther. (2011) 1:19-29. doi: 10.2147/BTAT.S17261

118. Lundqvist LCE, Rattigan D, Ehtesham E, Demmou C, Östenson CG, Sandström C. Profiling and activity screening of Dammarane-type triterpen saponins from Gynostemma pentaphyllum with glucose-dependent insulin secretory activity. Sci Rep. (2019) 9:627. doi: 10.1038/s41598-018-37517-3

119. Zheng X, Li P, Lu X. Research advances in cytochrome P450-catalysed pharmaceutical terpenoid biosynthesis in plants. J Exp Bot. (2019) 70:461930. doi: 10.1093/jxb/erz203

120. Haralampidis K, Trojanowska M, Osbourn AE. Biosynthesis of triterpenoid saponins in plants. Adv Biochem Eng Biotechnol. (2002) 75:31-49. doi: 10.1007/3-540-44604-4_2

121. Güçlü-Üstündag Ö, Mazza G. Saponins: properties, applications and processing. Crit Rev Food Sci Nutr. (2007) 47:231-58. doi: 10.1080/10408390600698197

122. Srivastava G, Sandeep Garg A, Misra RC, Chanotiya CS, Ghosh S. Transcriptome analysis and functional characterization of oxidosqualene cyclases of the arjuna triterpene saponin pathway. Plant Sci. (2020) 292:110382. doi: 10.1016/j.plantsci.2019.110382

123. Dong J, Liang W, Wang T, Sui J, Wang J, Deng Z, et al. Saponins regulate intestinal inflammation in colon cancer and IBD. Pharmacol Res. (2019) 144:66-72. doi: 10.1016/j.phrs.2019.04.010

124. Han Y, Chi J, Zhang M, Zhang R, Fan S, Dong L, et al. Changes in saponins, phenolics and antioxidant activity of quinoa (Chenopodium quinoa Willd) during milling process. LWT Food Sci Technol. (2019) 114:108381. doi: 10.1016/j.lwt.2019.108381

125. Tatiya AU, Dande PR, Mutha RE, Surana SJ. Effect of saponins from of Sesbania sesban L. (merr) on acute and chronic inflammation in experimental induced animals. J Biol Sci. (2013) 13:123-30. doi: $10.3923 /$ jbs.2013.123.130

126. Dinda B, Debnath S, Mohanta BC, Harigaya Y. Naturally occurring triterpenoid saponins. Chem Biodiv. (2010) 7:2327-580. doi: $10.1002 /$ cbdv. 200800070

127. Shah KA, Patel MB, Patel RJ, Parmar PK. Mangifera indica (mango). Pharmacogn Rev. (2010) 4:42-8. doi: 10.4103/0973-7847.65325

128. Shi ZN, Wang YD, Gong Y, Li HF, Zhu Y. New triterpenoid saponins with cytotoxic activities from Ligularia przewalskii. Phytochem Lett. (2019) 30:215-9. doi: 10.1016/j.phytol.2019.02.024

129. Bechkri S, Alabdul Magid A, Sayagh C, Berrehal D, Harakat D, Voutquenne-Nazabadioko L, et al. Triterpene saponins from Silene gallica collected in North-Eastern Algeria. Phytochemistry. (2020) 172:112274. doi: 10.1016/j.phytochem.2020.112274

130. Biang AEM, Kamto ELD, Simo LM, Antheaume C, Lavedan P, Vedrenne $\mathrm{M}$, et al. Triterpenoid saponins from the stem barks of Chytranthus klaineanus Radlk. ex Engl. Phytochem Lett. (2020) 37:37-41. doi: 10.1016/j.phytol.2020.04.006

131. Mohamed NM, Makboul MA, Farag SF, Wang YH, Mohamed SM, Ross SA. Chemosystematically valuable triterpenoid saponins from Glandularia × hybrida. Phytochemistry. (2020) 175:112367. doi: 10.1016/j.phytochem.2020.112367

132. Mazahery-Laghab H, Yazdi-Samadi B, Bagheri M, Bagheri AR. Alfalfa (Medicago sativa L.) shoot saponins: identification and bio-activity 
by the assessment of aphid feeding. Br J Nutr. (2011) 105:62-70. doi: 10.1017/S0007114510003120

133. Kołodziej B, Seczyk Ł, Sugier D, Kedzia B, Chernetskyy M, Gevrenova R, et al. Determination of the yield, saponin content and profile, antimicrobial and antioxidant activities of three Gypsophila species. Ind Crops Prod. (2019) 138:111422. doi: 10.1016/j.indcrop.2019.05.071

134. El Hazzam K, Hafsa J, Sobeh M, Mhada M, Taourirte M, El Kacimi K, et al. An insight into saponins from quinoa (Chenopodium quinoa Willd): a review. Molecules. (2020) 25:1059. doi: 10.3390/molecules 25051059

135. Ji S, Wang Y, Shao X, Zhu C, Lin Y, Gao S, et al. Extraction and purification of triterpenoid saponins from licorice by ionic liquid based extraction combined with in situ alkaline aqueous biphasic systems. Separ Purif Technol. (2020) 247:116953. doi: 10.1016/j.seppur.2020.116953

136. den Brok MH, Büll C, Wassink M, de Graaf AM, Wagenaars JA, Minderman $\mathrm{M}$, et al. Saponin-based adjuvants induce cross-presentation in dendritic cells by intracellular lipid body formation. Nat Commun. (2016) 7:13324. doi: 10.1038/ncomms 13324

137. Dong S, Yang X, Zhao L, Zhang F, Hou Z, Xue P. Antibacterial activity and mechanism of action saponins from Chenopodium quinoa Willd. husks against foodborne pathogenic bacteria. Ind Crops Prod. (2020) 149:112350. doi: 10.1016/j.indcrop.2020.112350

138. Qiu Y, He D, Yang J, Ma L, Zhu K, Cao Y. Kaempferol separated from Camellia oleifera meal by high-speed countercurrent chromatography for antibacterial application. Eur Food Res Technol. (2020) 246:2383-2397. doi: 10.1007/s00217-020-03582-0

139. Hamden K, Jaouadi B, Salami T, Carreau S, Bejar S, Elfeki A. Modulatory effect of fenugreek saponins on the activities of intestinal and hepatic disaccharidase and glycogen and liver function of diabetic rats. Biotechnol Bioprocess Eng. (2010) 15:745-53. doi: 10.1007/s12257-009-3159-0

140. Khan NA. Two antifungal active triterpenoid saponins from the seeds of Lathyrus plants. Nat Prod Res. (2011) 25:1687-94. doi: $10.1080 / 14786419.2011 .561205$

141. Hu Q, Chen YY, Jiao QY, Khan A, Li F, Han DF, et al. Triterpenoid saponins from the pulp of Sapindus mukorossi and their antifungal activities. Phytochemistry. (2018) 147:1-8. doi: 10.1016/j.phytochem.2017.12.004

142. Ngo MT, Han JW, Yoon S, Bae S, Kim SY, Kim H, et al. Discovery of new triterpenoid saponins isolated from Maesa japonica with antifungal activity against rice blast fungus Magnaporthe oryzae. J Agric Food Chem. (2019) 67:7706-15. doi: 10.1021/acs.jafc.9b02236

143. Hu JL, Nie SP, Huang DF, Li C, Xie MY. Extraction of saponin from Camellia oleifera cake and evaluation of its antioxidant activity. Int J Food Sci Technol. (2012) 47:1676-87. doi: 10.1111/j.1365-2621.2012.03020.x

144. Newbold CJ, El Hassan SM, Wang J, Ortega ME, Wallace RJ. Influence of foliage from African multipurpose trees on activity of rumen protozoa and bacteria. Br J Nutr. (1997) 78:237-49. doi: 10.1079/BJN19970143

145. Odenyo AA, Osuji PO, Karanfil O. Effect of multipurpose tree (MPT) supplements on ruminal ciliate protozoa. Anim Feed Sci Technol. (1997) 67:169-80. doi: 10.1016/S0377-8401(96)01118-2

146. Hristov AN, Ivan M, Neill L, McAllister TA. Evaluation of several potential bioactive agents for reducing protozoal activity in vitro. Anim Feed Sci Technol. (2003) 105:163-84. doi: 10.1016/S0377-8401(03)00060-9

147. Zhang D, Zhang Q, Zheng Y, Lu J. Anti-breast cancer and toxicity studies of total secondary saponin from Anemone raddeana Rhizome on MCF-7 cells via ROS generation and PI3K/AKT/mTOR inactivation. J Ethnopharmacol. (2020) 259:112984. doi: 10.1016/j.jep.2020.112984

148. Zhao YL, Cai GM, Hong X, Shan LM, Xiao XH. Anti-hepatitis B virus activities of triterpenoid saponin compound from Potentilla anserine $\mathrm{L}$. Phytomedicine. (2008) 15:253-8. doi: 10.1016/j.phymed.2008.01.005

149. Verma PK, Raina R, Agarwal S, Kaur H. Phytochemical ingredients and pharmacological potential of Calendula officinalis Linn. Pharma Biomed Res. (2018) 4:1-17. doi: 10.18502/pbr.v4i2.214

150. Gevrenova R, Zaharieva MM, Kroumov AD, Voutquenne-Nazabadioko L, Zheleva-Dimitrova D, Balabanova V, et al. Gypsophila saponins enhance the cytotoxicity of etoposide in HD-MY-Z lymphoma cells. Food Chem Toxicol. (2019) 133:110777. doi: 10.1016/j.fct.2019.110777

151. Yoshikawa M, Morikawa T, Li N, Nagatomo A, Li X, Matsuda H. Bioactive saponins and glycosides. XXIII. Triterpene saponins with gastroprotective effect from the seeds of camellia sinensis-theasaponins $\mathrm{e}_{3}, \mathrm{e}_{4}, \mathrm{e}_{5}, \mathrm{e}_{6}$, and $\mathrm{e}_{7}$. Chem Pharma Bull. (2005) 53:1559-64. doi: 10.1248/cpb.53.1559

152. Morikawa T, Li N, Nagatomo A, Matsuda H, Li X, Yoshikawa M. Triterpene saponins with gastroprotective effects from tea seed (the seeds of Camellia sinensis). J Nat Prod. (2006) 69:185-90. doi: 10.1021/np058097w

153. Voutquenne L, Lavaud C, Massiot G, Men-Olivier LL. Structure-activity relationships of haemolytic saponins. Pharma Biol. (2002) 40:253-62. doi: 10.1076/phbi.40.4.253.8470

154. Plohmann B, Bader G, Hiller K, Franz G. Immunomodulatory and antitumoral effects of triterpenoid saponins. Die Pharm. (1997) 52:953-7.

155. Mirhaghparast SK, Zibaee A, Hajizadeh J, Ramzi S. Toxicity and physiological effects of the tea seed saponin on Helicoverpa armigera. Biocatal Agric Biotechnol. (2020) 25:101597. doi: 10.1016/j.bcab.2020.101597

156. Subba A, Bharati M, Rai P, Saha D. Phytochemical composition of Heracleum nepalense D. Don fruit extracts and its activity against the larvae of Aedes albopictus (Diptera: Culicidae). Int J Trop Insect Sci. (2020) 40:373-83. doi: 10.1007/s42690-019-00088-5

157. Wojciechowski K, Orczyk M, Gutberlet T, Geue T. Complexation of phospholipids and cholesterol by triterpenic saponins in bulk and in monolayers. Biochim Biophys Acta. (2016) 1858:363-73. doi: 10.1016/j.bbamem.2015.12.001

158. Jeepipalli SPK, Du B, Sabitaliyevich UY, Xu B. New insights into potential nutritional effects of dietary saponins in protecting against the development of obesity. Food Chem. (2020) 318:126474. doi: 10.1016/j.foodchem.2020.126474

159. Li D, Liu D, Lv M, Gao P, Liu X. Isolation of triterpenoid saponins from Medicago sativa L. with neuroprotective activities. Bioorg Med Chem Lett. (2020) 30:126956. doi: 10.1016/j.bmcl.2020.126956

160. Potter DA, Redmond CT, Meepagala KM, Williams DW. Managing earthworm casts (Oligochaeta: Lumbricidae) in turfgrass using a natural byproduct of tea oil (Camellia sp.) manufacture. Pest Manage Sci. (2010) 66:439-46. doi: 10.1002/ps.1896

161. Zhu Z, Wen Y, Yi J, Cao Y, Liu F, McClements DJ. Comparison of natural and synthetic surfactants at forming and stabilizing nanoemulsions: Tea saponin, Quillaja saponin, and Tween 80. J Colloid Interface Sci. (2019) 536:80-7. doi: 10.1016/j.jcis.2018.10.024

162. Long J, Song J, Zhang X, Deng M, Xie L, Zhang L, et al. Tea saponins as natural stabilizers for the production of hesperidin nanosuspensions. Int $J$ Pharma. (2020) 583:119406. doi: 10.1016/j.ijpharm.2020.119406

163. Ku-Vera JC, Jiménez-Ocampo R, Valencia-Salazar SS, Montoya-Flores MD, Molina-Botero IC, Arango J, et al. Role of secondary plant metabolites on enteric methane mitigation in ruminants. Front Vet Sci. (2020) 7:584. doi: $10.3389 /$ fvets.2020.00584

164. Lu CD, Jorgensen NA. Alfalfa saponins affect site and extent of nutrient digestion in ruminants. J Nutr. (1987) 117:919-27. doi: 10.1093/jn/117.5.919

165. Ramírez-Restrepo CA, Tan C, O’Neill CJ, López-Villalobos N, Padmanabha J, Wang J, et al. Methane production, fermentation characteristics, and microbial profiles in the rumen of tropical cattle fed tea seed saponin supplementation. Anim Feed Sci Technol. (2016) 216:58-67. doi: 10.1016/j.anifeedsci.2016.03.005

166. Ramírez-Restrepo CA, O'Neill CJ, López-Villalobos N, Padmanabha J, Wang JK, McSweeney C. Effects of tea seed saponin supplementation on physiological changes associated with blood methane concentration in tropical Brahman cattle. Anim Prod Sci. (2016) 56:457-65. doi: 10.1071/AN15582

167. Mao HL, Wang JK, Zhou YY, Liu JX. Effects of addition of tea saponins and soybean oil on methane production, fermentation and microbial population in the rumen of growing lambs. Livestock Sci. (2010) 129:56-62. doi: 10.1016/j.livsci.2009.12.011

168. Zhou YY, Mao HL, Jiang F, Wang JK, Liu JX, McSweeney CS. Inhibition of rumen methanogenesis by tea saponins with reference to fermentation pattern and microbial communities in Hu sheep. Anim Feed Sci Technol. (2011) 166-167:93-100. doi: 10.1016/j.anifeedsci.2011. 04.007

169. Ramos-Morales E, Lyons L, de la Fuente G, Braganca R, Newbold CJ. Not all saponins have a greater antiprotozoal activity than their related sapogenins. FEMS Microbiol Lett. (2019) 366:fnz144. doi: 10.1093/femsle/fnz144 
170. Augustin JM, Kuzina V, Andersen SB, Bak S. Molecular activities, biosynthesis and evolution of triterpenoid saponins. Phytochemistry. (2011) 72:435-57. doi: 10.1016/j.phytochem.2011.01.015

171. Dourmashkin RR, Dougherty RM, Harris RJC. Electron microscopic observations on rous sarcoma virus and cell membranes. Nature. (1962) 194:1116-9. doi: 10.1038/1941116a0

172. Guo YQ, Liu JX, Lu Y, Zhu WY, Denman SE, McSweeney CS. Effect of tea saponin on methanogenesis, microbial community structure and expression of $m c r A$ gene, in cultures of rumen micro-organisms. Lett Appl Microbiol. (2008) 47:421-6. doi: 10.1111/j.1472-765X.2008.02459.x

173. Hu WL, Liu JX, Ye JA, Wu YM, Guo YQ. Effect of tea saponin on rumen fermentation in vitro. Anim Feed Sci Technol. (2005) 120:333-9. doi: 10.1016/j.anifeedsci.2005.02.029

174. Hu W, Liu J, Wu Y, Guo Y, Ye J. Effects of tea saponins on in vitro ruminal fermentation and growth performance in growing Boer goat. Archiv Anim Nutr. (2006) 60:89-97. doi: 10.1080/17450390500353119

175. Schulman JH, Rideal EK. Molecular interaction in monolayers II-the action of haemolytic and agglutinating agents on lipo-protein monolayers. Proc $R$ Soc Lond B Biol Sci. (1937) 122:46-57. doi: 10.1098/rspb.1937.0009

176. Bangham AD, Horne RW. Action of saponin on biological cell membranes. Nature. (1962) 196:952-3. doi: 10.1038/196952a0

177. Abreu A, Carulla JE, Lascano CE, Díaz TE, Kreuzer M, Hess HD. Effects of Sapindus saponaria fruits on ruminal fermentation and duodenal nitrogen flow of sheep fed a tropical grass diet with and without legume. J Anim Sci. (2004) 82:1392-400. doi: 10.2527/2004.8251392x

178. Jouany JP, Senaud J. Effect of rumen ciliates on the digestion of different carbohydrates in sheep. I. Utilization of cell wall carbohydrates (cellulose and hemicellulose) and of starch. Reprod Nutr Dev. (1982) 22:735-52.

179. Sidhu GS, Oakenfull DG. A mechanism for the hypocholesterolaemic activity of saponins. Br J Nutr. (1986) 55:643-9. doi: 10.1079/BJN19860070

180. Jenkins RA. Fine structure of division in ciliate protozoa: I. Micronuclear mitosis in blepharisma. J Cell Biol. (1967) 34:463-81. doi: $10.1083 /$ jcb.34.2.463

181. Goode D. Evolution of mitosis in protozoa: the association of chromosomes, nuclear envelope, kinetochores and microtubules. Biosystems. (1975) 7:31825. doi: 10.1016/0303-2647(75)90009-X

182. Chavali SR, Campbell JB. Adjuvant effects of orally administered saponins on humoral and cellular immune responses in mice. Immunobiology. (1987) 174:347-59. doi: 10.1016/S0171-2985(87)80009-8

183. Chavali SR, Francis T, Campbell JB. An in vitro study of immunomodulatory effects of some saponins. Int J Immunopharmacol. (1987) 9:675-83. doi: 10.1016/0192-0561(87)90038-5

184. Ramos-Morales E, de la Fuente G, Duval S, Wehrli C, Bouillon M, Lahmann $\mathrm{M}$, et al. Antiprotozoal effect of saponins in the rumen can be enhanced by chemical modifications in their structure. Front Microbiol. (2017) 8:399. doi: 10.3389/fmicb.2017.00399

185. Tan C, Ramírez-Restrepo CA, Shah AM, Hu R, Bell M, Wang Z, et al. The community structure and microbial linkage of rumen protozoa and methanogens in response to the addition of tea seed saponins in the diet of beef cattle. J Anim Sci Biotechnol. (2020) 11:80. doi: 10.1186/s40104-020-00491-w

186. Wang JK, Ye JA, Liu JX. Effects of tea saponins on rumen microbiota, rumen fermentation, methane production and growth performance-a review. Trop Anim Health Prod. (2012) 44:697-706. doi: 10.1007/s11250-011-9960-8

187. Liu Y, Ma T, Chen D, Zhang N, Si B, Deng K, et al. Effects of tea saponin supplementation on nutrient digestibility, methanogenesis, and ruminal microbial flora in dorper crossbred ewe. Animals. (2019) 9:29. doi: 10.3390/ani9010029

188. Yuan ZP, Zhang CM, Zhou L, Zou CX, Guo YQ, Li WT, et al. Inhibition of methanogenesis by tea saponin and tea saponin plus disodium fumarate in sheep. J Anim Feed Sci. (2007) 16:560-5. doi: 10.22358/jafs/74607/2007

189. McCrabb GJ, Hunter RA. Prediction of methane emissions from beef cattle in tropical production systems. Aust J Agric Res. (1999) 50:1335-40. doi: 10.1071/AR99009

190. Hess HD, Kreuzer M, Diaz TE, Lascano CE, Carulla JE, Soliva CR, et al. Saponin rich tropical fruits affect fermentation and methanogenesis in faunated and defaunated rumen fluid. Anim Feed Sci Technol. (2003) 109:7994. doi: 10.1016/S0377-8401(03)00212-8
191. Hess HD, Monsalve LM, Lascano CE, Carulla JE, Díaz TE, Kreuzer M. Supplementation of a tropical grass diet with forage legumes and Sapindus saponaria fruits: effects on in vitro ruminal nitrogen turnover and methanogenesis. Aust J Agric Res. (2003) 54:703-13. doi: 10.1071/AR02241

192. Molina-Botero IC, Arroyave-Jaramillo J, Valencia-Salazar S, BarahonaRosales R, Aguilar-Pérez CF, Ayala Burgos A, et al. Effects of tannins and saponins contained in foliage of Gliricidia sepium and pods of Enterolobium cyclocarpum on fermentation, methane emissions and rumen microbial population in crossbred heifers. Anim Feed Sci Technol. (2019) 251:1-11. doi: 10.1016/j.anifeedsci.2019.01.011

193. Liu JP, Lu D, Nicholson RC, Li PY, Wang F. Toxicity of a novel antitumor agent 20(S)-ginsenoside Rg3: a 26-week intramuscular repeated administration study in Beagle dogs. Food Chem Toxicol. (2011) 49:1718-27. doi: 10.1016/j.fct.2011.04.017

194. Johnson IT, Gee JM, Price K, Curl C, Fenwick GR. Influence of saponins on gut permeability and active nutrient transport in vitro. J Nutr. (1986) 116:2270-7. doi: 10.1093/jn/116.11.2270

195. Oleszek W, Nowacka J, Gee JM, Wortley GM, Johnson IT. Effects of some purified alfalfa (Medicago sativa) saponins on transmural potential difference in mammalian small intestine. J Sci Food Agric. (1994) 65:35-9. doi: 10.1002/jsfa.2740650107

196. Chakrabarti S, Jahandideh F, Wu J. Food-derived bioactive peptides on inflammation and oxidative stress. BioMed Res Int. (2014) 2014:608979. doi: $10.1155 / 2014 / 608979$

197. Bionaz M, Loor JJ. Ruminant metabolic systems biology: reconstruction and integration of transcriptome dynamics underlying functional responses of tissues to nutrition and physiological state. Gene Regul Syst Biol. (2012) 6:GRSB.S9852. doi: 10.4137/GRSB.S9852

198. Li Y, Meng Q, Yang M, Liu D, Hou X, Tang L, et al. Current trends in drug metabolism and pharmacokinetics. Acta Pharma Sin B. (2019) 9:1113-44. doi: 10.1016/j.apsb.2019.10.001

199. Kantae V, Krekels EHJ, Esdonk MJV, Lindenburg P, Harms AC, Knibbe CAJ, et al. Integration of pharmacometabolomics with pharmacokinetics and pharmacodynamics: towards personalized drug therapy. Metabolomics. (2017) 13:9-9. doi: 10.1007/s11306-016-1143-1

200. Francis G, Kerem Z, Makkar HPS, Becker K. The biological action of saponins in animal systems: a review. Br J Nutr. (2002) 88:587-605. doi: 10.1079/BJN2002725

201. Podolak I, Galanty A, Sobolewska D. Saponins as cytotoxic agents: a review. Phytochem Rev. (2010) 9:425-74. doi: 10.1007/s11101-010-9183-z

202. Wina E, Muetzel S, Becker K. The impact of saponins or saponin-containing plant materials on ruminant production-a review. J Agric Food Chem. (2005) 53:8093-105. doi: 10.1021/jf048053d

203. Wina E. Saponins: effects on rumen microbial ecosystem and metabolism in the rumen. In: Patra AK, editor. Dietary Phytochemicals and Microbes. Dordrecht: Springer Netherlands (2012). p. 311-50.

204. Azimova SS. Natural Compounds - Triterpene Glycosides. Part 1 and Part 2. New York, NY: Springer-Verlag (2013).

205. Fu J, Wu H, Wu H, Deng R, Li F. Chemical and metabolic analysis of Achyranthes bidentate saponins with intestinal microflora-mediated biotransformation by ultra-performance liquid chromatography-quadrupole time-of-flight mass spectrometry coupled with metabolism platform. J Pharma Biomed Anal. (2019) 170:305-20. doi: 10.1016/j.jpba.2019.03.041

206. Huang FQ, Dong X, Yin X, Fan Y, Fan Y, Mao C, et al. A mass spectrometry database for identification of saponins in plants. J Chromatogr A. (2020) 1625:461296. doi: 10.1016/j.chroma.2020.461296

207. Orczyk M, Wojciechowski K, Brezesinski G. The influence of steroidal and triterpenoid saponins on monolayer models of the outer leaflets of human erythrocytes, E. coli and S. cerevisiae cell membranes. J Colloid Interface Sci. (2020) 563:207-17. doi: 10.1016/j.jcis.2019.12.014

208. Yao L, Lu J, Wang J, Gao WY. Advances in biosynthesis of triterpenoid saponins in medicinal plants. Chinese J Nat Med. (2020) 18:417-24. doi: 10.1016/S1875-5364(20)30049-2

209. Sahari MA, Amooi M. Tea seed oil: extraction, compositions, applications, functional and antioxidant properties. Acad J Med Plants. (2013) 1:68-79. doi: 10.15413/ajmp.2012.0113

210. Obasi TC, Moldovan R, Toiu A, Braicu C, Bodoki E, Berindan-Neagoe $\mathrm{I}$, et al. Molecular-trapping in emulsion's monolayer: a new strategy for 
production and purification of bioactive saponins. Sci Rep. (2017) 7:14511. doi: 10.1038/s41598-017-15067-4

211. Selvamuthukumaran M, Shi J. Recent advances in extraction of antioxidants from plant by-products processing industries. Food Qual Saf. (2017) 1:61-81. doi: 10.1093/fqsafe/fyx004

212. Wen B, Tian JM, Huang ZR, Xiao SJ, Yuan WL, Wang JX, et al. Triterpenoid saponins from the roots of Psammosilene tunicoides. Fitoterapia. (2020) 144:104596. doi: 10.1016/j.fitote.2020.104596

213. National Academies of Sciences, Engineering, and Medicine. Nutrient Requirements of Beef Cattle. Washington, DC: National Academy Press (2016).

214. Cabiddu A, Delgadillo-Puga C, Decandia M, Molle G. Extensive ruminant production systems and milk quality with emphasis on unsaturated fatty acids, volatile compounds, antioxidant protection degree and phenol content. Animals. (2019) 9:771. doi: 10.3390/ani9100771

215. Vasconcelos JT, Galyean ML. Nutritional recommendations of feedlot consulting nutritionists: The 2007 Texas Tech University survey. J Anim Sci. (2007) 85:2772-81. doi: 10.2527/jas.2007-0261

216. Lucas A, Coulon JB, Agabriel C, Chilliard Y, Rock E. Relationships between the conditions of goat's milk production and the contents of some components of nutritional interest in Rocamadour cheese. Small Rumin Res. (2008) 74:91-106. doi: 10.1016/j.smallrumres.2007.04.001

217. Mariaca RG, Berger TFH, Gauch R, Imhof MI, Jeangros B, Bosset JO. Occurrence of volatile mono- and sesquiterpenoids in highland and lowland plant species as possible precursors for flavor compounds in milk and dairy products. J Agric Food Chem. (1997) 45:4423-34. doi: 10.1021/jf9 $70216 \mathrm{t}$

218. Pizzoferrato L, Manzi P, Marconi S, Fedele V, Claps S, Rubino R. Degree of antioxidant protection: a parameter to trace the origin and quality of goat's milk and cheese. J Dairy Sci. (2007) 90:4569-74. doi: 10.3168/jds.2007-0093

219. Chauhan SS, Celi P, Ponnampalam EN, Leury BJ, Liu F, Dunshea FR. Antioxidant dynamics in the live animal and implications for ruminant health and product (meat/milk) quality: role of vitamin $\mathrm{E}$ and selenium. Anim Prod Sci. (2014) 54:1525-36. doi: 10.1071/AN14334

220. Plascencia A, Montano-Gomez MF, Salinas-Chavira J, Torrentera-Olivera NG, Zinn RA. Influence of supplemental tocopherol level (0,250 and $500 \mathrm{IU}$ $R R R$ - $\alpha$-tocopherol/d/steer) and injectable retinol form (retinyl propionate vs retinyl palmitate) on growth performance, carcass characteristics and plasma concentration in calf-fed Holstein steers. J Appl Anim Res. (2018) 46:1516-21. doi: 10.1080/09712119.2018.1552153

221. Nozière P, Graulet B, Lucas A, Martin B, Grolier P, Doreau M. Carotenoids for ruminants: from forages to dairy products. Anim Feed Sci Technol. (2006) 131:418-50. doi: 10.1016/j.anifeedsci.2006.06.018

222. van den Berg H, Faulks R, Granado HF, Hirschberg J, Olmedilla B, Sandmann $\mathrm{G}$, et al. The potential for the improvement of carotenoid levels in foods and the likely systemic effects. J Sci Food Agric. (2000) 80:880-912. doi: 10.1002/ (SICI) 1097-0010(20000515)80:7<880::AID-JSFA646>3.0.CO;2-1

223. Asadian A, Mézes M. Effects of vitamins A and E supplementation on vitamins $\mathrm{A}$ and $\mathrm{E}$ status of blood plasma, liver and tail fat of fattailed sheep. Small Rumin Res. (1996) 23:1-6. doi: 10.1016/S0921-4488(96) 00903-0

224. Alosilla CE Jr, McDowell LR, Wilkinson NS, Staples CR, Thatcher WW, Martin FG, et al. Bioavailability of vitamin A sources for cattle. J Anim Sci. (2007) 85:1235-8. doi: 10.2527/jas.2006-251

225. Rucker RB, Morris J, Fascetti AJ. Chapter 23 - vitamins. In: Kaneko JJ, Harvey JW, Bruss ML, editors. Clinical Biochemistry of Domestic Animals, 6th ed. San Diego, CA: Academic Press (2008). p. 695-730.

226. Hashem NM, Abu-Tor EM, Abo-Elezz ZR, Latif MGA. Relevance of antioxidant vitamin supplementation for improvement of milk production, milk quality and energy status of lactating ewes. Small Rumin Res. (2019) 177:153-9. doi: 10.1016/j.smallrumres.2019.07.002

227. Saribey M, Karaca S. Effects of pre-slaughter ascorbic acid administration on some physiological stress response and meat quality traits of lambs and kids subjected to road transport. Anim Prod Sci. (2019) 59:954-64. doi: 10.1071/AN17554

228. Mohamed HE, Alhaidary A, Beynen AC. Habitual diet and ascorbic acid status in Sudanese camels. Trop Anim Health Prod. (2013) 45:887-8. doi: $10.1007 /$ s11250-013-0365-8
229. Nudda A, Atzori AS, Correddu F, Battacone G, Lunesu MF, Cannas A, et al. Effects of nutrition on main components of sheep milk. Small Rumin Res. (2020) 184:106015. doi: 10.1016/j.smallrumres.2019.11.001

230. Cusack PMV, McMeniman NP, Lean IJ. Effects of injectable vitamins $\mathrm{A}, \mathrm{D}, \mathrm{E}$ and $\mathrm{C}$ on the health and growth rate of feedlot cattle destined for the Australian domestic market. Aust Vet J. (2008) 86:81-7. doi: 10.1111/j.1751-0813.2008.00255.x

231. Duplessis M, Girard CL, Santschi DE, Laforest JP, Durocher J, Pellerin D. Effects of folic acid and vitamin B12 supplementation on culling rate, diseases, and reproduction in commercial dairy herds. J Dairy Sci. (2014) 97:2346-54. doi: 10.3168/jds.2013-7369

232. Chirase NK, Greene LW, Purdy CW, Loan RW, Auvermann BW, Parker $\mathrm{DB}$, et al. Effect of transport stress on respiratory disease, serum antioxidant status, and serum concentrations of lipid peroxidation biomarkers in beef cattle. Am J Vet Res. (2004) 65:860-4. doi: 10.2460/ajvr.2004.65.860

233. Wernicki A, Urban-Chmiel R, Puchalski A, Dec M. Evaluation of the influence of transport and adaptation stress on chosen immune and oxidative parameters and occurrence of respiratory syndrome in feedlot calves. Bull Vet Inst Pulawy. (2014) 58:111-6. doi: 10.2478/bvip-2014-0018

234. Russell JR, Sexten WJ, Kerley MS, Hansen SL. Relationship between antioxidant capacity, oxidative stress, and feed efficiency in beef steers. $J$ Anim Sci. (2016) 94:2942-53. doi: 10.2527/jas.2016-0271

235. Maiorano G, Angwech H, Memmo DD, Wilkanowska A, Mucci R, Abiuso C, et al. Effects of intramuscular vitamin E multiple injection on quality, oxidative stability and consumer acceptability of meat from Laticauda lambs fed under natural rearing conditions. Small Rumin Res. (2016) 139:52-9. doi: 10.1016/j.smallrumres.2016.05.004

236. Maraba KP, Mlambo V, Yusuf AO, Marume U, Hugo A. Extra dietary vitamin $\mathrm{E}$ - selenium as a mitigation strategy against housing-induced stress in Dohne Merino lambs: effect on growth performance, stress biomarkers, and meat quality. Small Rumin Res. (2018) 160:31-7. doi: 10.1016/j.smallrumres.2018.01.009

237. Rode LM, McAllister TA, Cheng KJ. Microbial degradation of vitamin a in rumen fluid from steers fed concentrate, hay or straw diets. Can J Anim Sci. (1990) 70:227-33. doi: 10.4141/cjas90-026

238. Hemingway RG, Parkins JJ, Ritchie NS. Enhanced reproductive performance of ewes given a sustained-release multi-trace element/vitamin ruminal bolus. Small Rumin Res. (2001) 39:25-30. doi: 10.1016/S0921-4488(00)00175-9

239. Decandia M, Cabiddu A, Molle G, Branca A, Epifani G, Pintus S, et al. Effect of different feeding systems on fatty acid composition and volatile compound content in goat milk. Options Mediterr A. (2007) 74:129-34.

240. Biondi L, Valvo MA, Di Gloria M, Tenghi ES, Galofaro V, Priolo A. Changes in ewe milk fatty acids following turning out to pasture. Small Rumin Res. (2008) 75:17-23. doi: 10.1016/j.smallrumres.2007.07.004

241. Hashem NM, Abd-Elrazek D, Abo-Elezz ZR, Latif MGA. Effect of vitamin A or $\mathrm{C}$ on physiological and reproductive response of Rahmani ewes during subtropical summer breeding season. Small Rumin Res. (2016) 144:313-9. doi: 10.1016/j.smallrumres.2016.10.013

242. Buchin S, Martin B, Dupont D, Bornard A, Achilleos C. Influence of the composition of Alpine highland pasture on the chemical, rheological and sensory properties of cheese. J Dairy Res. (1999) 66:579-88. doi: $10.1017 /$ S0022029999003842

243. Pfister JA, Panter KE, Gardner DR, Stegelmeier BL, Ralphs MH, Molyneux RJ, et al. Alkaloids as anti-quality factors in plants on western U.S. rangelands. J Range Manage. (2011) 54:447-61. doi: 10.2307/4003116

244. Collins M, Missaoui AM, Hill NS. Forage-related animal disorders. In: Collins M, Nelson CJ, Moore KJ, BarnesRF, editors. Forages: An Introduction to Grassland Agriculture, 7th ed. New York, NY: John Wiley \& Sons, Inc. (2018). p. 301-20.

245. Molyneux RJ, Gardner DL, Colegate SM, Edgar JA. Pyrrolizidine alkaloid toxicity in livestock: a paradigm for human poisoning? Food Addit Contamin A. (2011) 28:293-307. doi: 10.1080/19440049.2010.547519

246. Boppré M. The ecological context of pyrrolizidine alkaloids in food, feed and forage: an overview. Food Additi Contamin A. (2011) 28:260-81. doi: 10.1080/19440049.2011.555085

247. Lisonbee LD, Villalba JJ, Provenza FD. Effects of tannin on selection by sheep of forages containing alkaloids, tannins and saponins. J Sci Food Agric. (2009) 89:2668-77. doi: 10.1002/jsfa.3772 
248. Cardoso MZ. Testing chemical defence based on pyrrolizidine alkaloids. Anim Behav. (1997) 54:985-91. doi: 10.1006/anbe.1997.0505

249. Lodge-Ivey SL, Rappe MS, Johnston WH, Bohlken RE, Craig AM. Molecular analysis of a consortium of ruminal microbes that detoxify pyrrolizidine alkaloids. Can J Microbiol. (2005) 51:455-65. doi: 10.1139/w05-026

250. Klotz JL, Nicol AM. Ergovaline, an endophytic alkaloid. 1. Animal physiology and metabolism. Anim Prod Sci. (2016) 56:1761-74. doi: 10.1071/AN14962

251. Nicol AM, Klotz JL. Ergovaline, an endophytic alkaloid. 2. Intake and impact on animal production, with reference to New Zealand. Anim Prod Sci. (2016) 56:1775-86. doi: 10.1071/AN14963

252. Ehteshamfar SM, Akhbari M, Afshari JT, Seyedi M, Nikfar B, ShapouriMoghaddam A, et al. Anti-inflammatory and immune-modulatory impacts of berberine on activation of autoreactive $\mathrm{T}$ cells in autoimmune inflammation. J Cell Mol Med. (2020) 24:13573-88. doi: 10.1111/jcmm.16049

253. Li X, Ge J, Zheng Q, Zhang J, Sun R, Liu R. Evodiamine and rutaecarpine from Tetradium ruticarpum in the treatment of liver diseases. Phytomedicine. (2020) 68:153180. doi: 10.1016/j.phymed.2020.153180

254. Limanaqi F, Biagioni F, Mastroiacovo F, Polzella M, Lazzeri G, Fornai F. Merging the multi-target effects of phytochemicals in neurodegeneration: from oxidative stress to protein aggregation and inflammation. Antioxidants. (2020) 9:1022. doi: 10.3390/antiox9101022

255. Ayemele AG, Ma L, Park T, Xu J, Yu Z, Bu D. Giant milkweed (Calotropis gigantea): a new plant resource to inhibit protozoa and decrease ammoniagenesis of rumen microbiota in vitro without impairing fermentation. Sci Total Environ. (2020) 743:140665. doi: 10.1016/j.scitotenv.2020.140665

256. Szulc $\mathrm{P}$, Mravčáková $\mathrm{D}$, Szumacher-Strabel M, Váradyová Z, Várady $\mathrm{M}$, Cobanová $\mathrm{K}$, et al. Ruminal fermentation, microbial population and lipid metabolism in gastrointestinal nematode-infected lambs fed a diet supplemented with herbal mixtures. PLoS ONE. (2020) 15:e0231516. doi: 10.1371/journal.pone. 0231516

257. Melchior EA, Myer PR. Fescue toxicosis and its influence on the rumen microbiome: mitigation of production losses through clover isoflavones. $J$ Appl Anim Res. (2018) 46:1280-8. doi: 10.1080/09712119.2018.1496920

258. Koester LR, Poole DH, Serão NVL, Schmitz-Esser S. Beef cattle that respond differently to fescue toxicosis have distinct gastrointestinal tract microbiota. PLoS ONE. (2020) 15:e0229192. doi: 10.1371/journal.pone.0229192

259. Rathbone DA, Bruce NC. Microbial transformation of alkaloids. Curr Opin Microbiol. (2002) 5:274-81. doi: 10.1016/S1369-5274(02)00317-X

260. Urdang G. The origin and development of the essential oil industry. In: Guenther E, editor. The Essential Oils: History, Origin in Plants, Production, Analysis. New York, NY: D. Van Nostrand Company, Inc. (1948). p. 3-13.

261. Giannenas I, Christaki-Sarikaki E, Bonos E, Florou-Paneri P. Essential oils and their applications in animal nutrition. Med Aromat Plants. (2013) 2:1-12. doi: 10.4172/2167-0412.1000140

262. Bakkali F, Averbeck S, Averbeck D, Idaomar M. Biological effects of essential oils-a review. Food Chem Toxicol. (2008) 46:446-75. doi: 10.1016/j.fct.2007.09.106

263. Dorman HJD, Deans SG. Antimicrobial agents from plants: antibacterial activity of plant volatile oils. J Appl Microbiol. (2000) 88:308-16. doi: 10.1046/j.1365-2672.2000.00969.x

264. Benchaar C, Calsamiglia S, Chaves AV, Fraser GR, Colombatto D, McAllister TA, et al. A review of plant-derived essential oils in ruminant nutrition and production. Anim Feed Sci Technol. (2008) 145:209-28. doi: 10.1016/j.anifeedsci.2007.04.014

265. Simitzis PE. Enrichment of animal diets with essential oils-a great perspective on improving animal performance and quality characteristics of the derived products. Medicines. (2017) 4:35. doi: 10.3390/medicines 4020035

266. Ultee A, Bennik MHJ, Moezelaar R. The phenolic hydroxyl group of carvacrol is essential for action against the food-borne pathogen Bacillus cereus. Appl Environ Microbiol. (2002) 68:1561-8. doi: 10.1128/aem.68.4.1561-1568.2002

267. Helander IM, Alakomi HL, Latva-Kala K, Mattila-Sandholm T, Pol I, Smid EJ, et al. Characterization of the action of selected essential oil components on gram-negative bacteria. J Agric Food Chem. (1998) 46:35905. doi: $10.1021 / \mathrm{j} f 980154 \mathrm{~m}$
268. Khiaosa-ard R, Zebeli Q. Meta-analysis of the effects of essential oils and their bioactive compounds on rumen fermentation characteristics and feed efficiency in ruminants. J Anim Sci. (2013) 91:1819-30. doi: 10.2527/jas.2012-5691

269. Bergen WG, Bates DB. Ionophores: their effect on production efficiency and mode of action. J Anim Sci. (1984) 58:1465-83.

270. Fandiño I, Calsamiglia S, Ferret A, Blanch M. Anise and capsicum as alternatives to monensin to modify rumen fermentation in beef heifers fed a high concentrate diet. Anim Feed Sci Technol. (2008) 145:409-17. doi: 10.1016/j.anifeedsci.2007.04.018

271. Meyer NF, Erickson GE, Klopfenstein TJ, Greenquist MA, Luebbe MK, Williams $\mathrm{P}$, et al. Effect of essential oils, tylosin, and monensin on finishing steer performance, carcass characteristics, liver abscesses, ruminal fermentation, and digestibilityl. J Anim Sci. (2009) 87:2346-54. doi: $10.2527 /$ jas.2008-1493

272. Khorrami B, Vakili AR, Mesgaran MD, Klevenhusen F. Thyme and cinnamon essential oils: Potential alternatives for monensin as a rumen modifier in beef production systems. Anim Feed Sci Technol. (2015) 200:816. doi: 10.1016/j.anifeedsci.2014.11.009

273. Meschiatti MAP, Gouvêa VN, Pellarin LA, Batalha CDA, Biehl MV, Acedo TS, et al. Feeding the combination of essential oils and exogenous $\alpha$-amylase increases performance and carcass production of finishing beef cattle. J Anim Sci. (2019) 97:456-71. doi: 10.1093/jas/sky415

274. Silva RB, Pereira MN, Araujo RC, Silva WR, Pereira RAN. A blend of essential oils improved feed efficiency and affected ruminal and systemic variables of dairy cows. Transl Anim Sci. (2020) 4:182-93. doi: $10.1093 /$ tas/txz183

275. Vakili AR, Khorrami B, Mesgaran MD, Parand E. The effects of thyme and cinnamon essential oils on performance, rumen fermentation and blood metabolites in holstein calves consuming high concentrate diet. Asian Australas J Anim Sci. (2013) 26:935-44. doi: 10.5713/ajas.2012.12636

276. Benchaar C, Lettat A, Hassanat F, Yang WZ, Forster RJ, Petit HV, et al. Eugenol for dairy cows fed low or high concentrate diets: effects on digestion, ruminal fermentation characteristics, rumen microbial populations and milk fatty acid profile. Anim Feed Sci Technol. (2012) 178:139-50. doi: 10.1016/j.anifeedsci.2012.10.005

277. Tomkins NW, Denman SE, Pilajun R, Wanapat M, McSweeney CS, Elliott R. Manipulating rumen fermentation and methanogenesis using an essential oil and monensin in beef cattle fed a tropical grass hay. Anim Feed Sci Technol. (2015) 200:25-34. doi: 10.1016/j.anifeedsci.2014.11.013

278. Beauchemin KA, McGinn SM. Methane emissions from beef cattle: effects of fumaric acid, essential oil, and canola oil. J Anim Sci. (2006) 48:1489-96. doi: $10.2527 / 2006.8461489 x$

279. Silva GG, Takiya CS, Del Valle TA, de Jesus EF, Grigoletto NTS, Nakadonari $B$, et al. Nutrient digestibility, ruminal fermentation, and milk yield in dairy cows fed a blend of essential oils and amylase. J Dairy Sci. (2018) 101:9815-26. doi: 10.3168/jds.2018-14789

280. Benchaar C, Petit HV, Berthiaume R, Ouellet DR, Chiquette J, Chouinard PY. Effects of essential oils on digestion, ruminal fermentation, rumen microbial populations, milk production, and milk composition in dairy cows fed alfalfa silage or corn silage. J Dairy Sci. (2007) 90:886-97. doi: 10.3168/jds.S0022-0302(07)71572-2

281. Vendramini THA, Takiya CS, Silva TH, Zanferari F, Rentas MF, Bertoni JC, et al. Effects of a blend of essential oils, chitosan or monensin on nutrient intake and digestibility of lactating dairy cows. Anim Feed Sci Technol. (2016) 214:12-21. doi: 10.1016/j.anifeedsci.2016.01.015

282. Tedeschi LO, Fox DG, Tylutki TP. Potential environmental benefits of ionophores in ruminant diets. J Environ Qual. (2003) 32:1591-602. doi: $10.2134 /$ jeq2003.1591

283. Benchaar C, Petit HV, Berthiaume R, Whyte TD, Chouinard PY. Effects of addition of essential oils and monensin premix on digestion, ruminal fermentation, milk production, and milk composition in dairy cows. J Dairy Sci. (2006) 89:4352-64. doi: 10.3168/jds.S0022-0302(06)72482-1

284. Benchaar C. Diet supplementation with cinnamon oil, cinnamaldehyde, or monensin does not reduce enteric methane production of dairy cows. Animal. (2016) 10:418-25. doi: 10.1017/S175173111500230X

285. Benchaar C. Feeding oregano oil and its main component carvacrol does not affect ruminal fermentation, nutrient utilization, methane emissions, milk 
production, or milk fatty acid composition of dairy cows. J Dairy Sci. (2020) 103:1516-27. doi: 10.3168/jds.2019-17230

286. Hosoda K, Nishida T, Park WY, Eruden B. Influence of Mentha $\times$ piperita L. (peppermint) supplementation on nutrient digestibility and energy metabolism in lactating dairy cows. Asian Australas J Anim Sci. (2005) 18:1721-6. doi: 10.5713/ajas.2005.1721

287. Kolling GJ, Stivanin SCB, Gabbi AM, Machado FS, Ferreira AL, Campos $\mathrm{MM}$, et al. Performance and methane emissions in dairy cows fed oregano and green tea extracts as feed additives. J Dairy Sci. (2018) 101:4221-34. doi: $10.3168 /$ jds.2017-13841

288. Elcoso G, Zweifel B, Bach A. Effects of a blend of essential oils on milk yield and feed efficiency of lactating dairy cows. Appl Anim Sci. (2019) 35:304-11. doi: 10.15232/aas.2018-01825

289. Hart KJ, Jones HG, Waddams KE, Worgan HJ, Zweifel B, Newbold CJ. An essential oil blend decreases methane emissions and increases milk yield in dairy cows. Open J Anim Sci. (2019) 9:259-67. doi: 10.4236/ojas.2019.93022

290. Castillo C, Benedito JL, Vázquez P, Pereira V, Méndez J, Sotillo J, et al. Effects of supplementation with plant extract product containing carvacrol, cinnamaldehyde and capsaicin on serum metabolites and enzymes during the finishing phase of feedlot-fed bull calves. Anim Feed Sci Technol. (2012) 171:246-50. doi: 10.1016/j.anifeedsci.2011.11.006

291. Oh J, Harper M, Giallongo F, Bravo DM, Wall EH, Hristov AN. Effects of rumen-protected Capsicum oleoresin on productivity and responses to a glucose tolerance test in lactating dairy cows. J Dairy Sci. (2017) 100:1888901. doi: 10.3168/jds.2016-11665

292. Yang WZ, Ametaj BN, Benchaar C, Beauchemin KA. Dose response to cinnamaldehyde supplementation in growing beef heifers: ruminal and intestinal digestion1. J Anim Sci. (2010) 88:680-8. doi: 10.2527/jas.2008-1652

293. Yang WZ, Benchaar C, Ametaj BN, Beauchemin KA. Dose response to eugenol supplementation in growing beef cattle: ruminal fermentation and intestinal digestion. Anim Feed Sci Technol. (2010) 158:57-64. doi: 10.1016/j.anifeedsci.2010.03.019

294. McIntosh FM, Williams P, Losa R, Wallace RJ, Beever DA, Newbold CJ. Effects of essential oils on ruminal microorganisms and their protein metabolism. Appl Environ Microbiol. (2003) 69:5011-4. doi: 10.1128/aem.69.8.5011-5014.2003

295. Osmari MP, Branco AF, Goes RHTB, Diaz TG, Matos LF. Increasing dietary doses of cashew nut shell liquid on rumen and intestinal digestibility of nutrient in steers fed a high-grain diet. Archiv Zoot. (2017) 66:375-81. doi: 10.21071/az.v66i255.2513

296. Olijhoek DW, Hellwing ALF, Grevsen K, Haveman LS, Chowdhury MR, Løvendahl P, et al. Effect of dried oregano (Origanum vulgare L.) plant material in feed on methane production, rumen fermentation, nutrient digestibility, and milk fatty acid composition in dairy cows. J Dairy Sci. (2019) 102:9902-18. doi: 10.3168/jds.2019-16329

297. Oh J, Harper M, Giallongo F, Bravo DM, Wall EH, Hristov AN. Effects of rumen-protected Capsicum oleoresin on immune responses in dairy cows intravenously challenged with lipopolysaccharide. J Dairy Sci. (2017) 100:1902-13. doi: 10.3168/jds.2016-11666

298. Hassan A, Abu Hafsa SH, Elghandour MMY, Kanth Reddy PR, Salem MZM, Anele UY, et al. Influence of Corymbia citriodora leaf extract on growth performance, ruminal fermentation, nutrient digestibility, plasma antioxidant activity and faecal bacteria in young calves. Anim Feed Sci Technol. (2020) 261:114394. doi: 10.1016/j.anifeedsci.2020. 114394

299. Katsoulos PD, Karatzia MA, Dovas CI, Filioussis G, Papadopoulos E, Kiossis E, et al. Evaluation of the in-field efficacy of oregano essential oil administration on the control of neonatal diarrhea syndrome in calves. Res Vet Sci. (2017) 115:478-83. doi: 10.1016/j.rvsc.2017.07.029

300. Belanche A, Newbold CJ, Morgavi DP, Bach A, Zweifel B, Yáñez-Ruiz DR. A meta-analysis describing the effects of the essential oils blend agolin ruminant on performance, rumen fermentation and methane emissions in dairy cows. Animals. (2020) 10:620. doi: 10.3390/ani10040620

301. Torres RNS, Moura DC, Ghedini CP, Ezequiel JMB, Almeida MTC. Meta-analysis of the effects of essential oils on ruminal fermentation and performance of sheep. Small Rumin Res. (2020) 189:106148. doi: 10.1016/j.smallrumres.2020.106148

302. Garcia MV, Matias J, Barros JC, Lima DP, Lopes RS, Andreotti R. Chemical identification of Tagetes minuta Linnaeus (Asteraceae) essential oil and its acaricidal effect on ticks. Rev Brasil Parasitol Vet. (2012) 21:405-11. doi: 10.1590/S1984-29612012000400011

303. Araújo LX, Novato TPL, Zeringota V, Maturano R, Melo D, Da Silva BC, et al. Synergism of thymol, carvacrol and eugenol in larvae of the cattle tick, Rhipicephalus microplus, and brown dog tick, Rhipicephalus sanguineus. Med Vet Entomol. (2016) 30:377-82. doi: 10.1111/mve.12181

304. Shezryna S, Anisah N, Saleh I, Syamsa RA. Acaricidal activity of the essential oils from Citrus hystrix (Rutaceae) and Cymbopogon citratus (Poaceae) on the cattle tick Rhipicephalus (Boophilus) microplus larvae (Acari: Ixodidae). Trop Biomed. (2020) 37:433-42.

305. Khater HF, Ramadan MY, El-Madawy RS. Lousicidal, ovicidal and repellent efficacy of some essential oils against lice and flies infesting water buffaloes in Egypt. Vet Parasitol. (2009) 164:257-66. doi: 10.1016/j.vetpar.2009.06.011

306. Zhu JJ, Berkebile DR, Dunlap CA, Zhang A, Boxler D, Tangtrakulwanich K, et al. Nepetalactones from essential oil of Nepeta cataria represent a stable fly feeding and oviposition repellent. Med Vet Entomol. (2012) 26:131-8. doi: 10.1111/j.1365-2915.2011.00972.x

307. Lachance S, Grange G. Repellent effectiveness of seven plant essential oils, sunflower oil and natural insecticides against horn flies on pastured dairy cows and heifers. Med Vet Entomol. (2014) 28:193-200. doi: $10.1111 /$ mve.12044

308. Pan L, Bu DP, Wang JQ, Cheng JB, Sun XZ, Zhou LY, et al. Effects of Radix Bupleuri extract supplementation on lactation performance and rumen fermentation in heat-stressed lactating Holstein cows. Anim Feed Sci Technol. (2014) 187:1-8. doi: 10.1016/j.anifeedsci.2013.09.008

309. Reza-Yazdi K, Fallah M, Khodaparast M, Kateb F, Hosseini-Ghaffari M. Effects of specific essential oil compounds on, feed intake, milk production, and ruminal environment in dairy cows during heat exposure. Int J Anim Vet Sci. (2014) 8:1393-7. doi: 10.5281/zenodo.1097455

310. Cheng J, Fan C, Sun X, Wang J, Zheng N, Zhang X, et al. Effects of Bupleurum extract on blood metabolism, antioxidant status and immune function in heat-stressed dairy cows. J Integr Agric. (2018) 17:657-63. doi: 10.1016/S2095-3119(17)61801-X

Conflict of Interest: The authors declare that the research was conducted in the absence of any commercial or financial relationships that could be construed as a potential conflict of interest.

Copyright (C) 2021 Tedeschi, Muir, Naumann, Norris, Ramírez-Restrepo and Mertens-Talcott. This is an open-access article distributed under the terms of the Creative Commons Attribution License (CC BY). The use, distribution or reproduction in other forums is permitted, provided the original author(s) and the copyright owner(s) are credited and that the original publication in this journal is cited, in accordance with accepted academic practice. No use, distribution or reproduction is permitted which does not comply with these terms. 